\title{
Thermal performance of an active-passive ventilation wall with phase change material in solar greenhouses
}

Chao Chen ${ }^{1, *}$, Haoshu Ling ${ }^{1,2, *}$, Zhiqiang (John) Zhai ${ }^{3}$, Yin Li ${ }^{1}$, Fengguang Yang ${ }^{1}$, Fengtao $\mathrm{Han}^{1}$, Shen $\mathrm{Wei}^{4}$

1. College of Architecture and Civil Engineering, Beijing University of Technology, Beijing 100124, P R China

2. Institute of Engineering Thermophysics, Chinese Academy of Sciences, Beijing 100190, P R China

3. Department of Civil, Environmental, and Architectural Engineering, University of Colorado at Boulder, Boulder, CO 80309-0428, USA

4. Bartlett School of Construction and Project Management, University College London (UCL), 2nd Floor 1-19 Torrington Place, London, WC1E 7HB, UK

\begin{abstract}
Using phase change material (PCM) in the north wall of solar greenhouses has been recommended as an efficient solution for promoting their indoor thermal environment. In this type of walls, however, there is always a thermal-stable layer, which would greatly decrease their heat storage capacity. To solve this problem, an active-passive ventilation wall with PCM has been developed in this study, and a comparative study was carried out using both experimental and numerical methods to justify its advantages over conventional walls. Several important parameters have been monitored or calculated to reflect the contribution of the newly proposed method to the performance of the middle layer of the wall, the indoor thermal environment and the plants' growth. The obtained results confirmed the great effectiveness of the proposed wall in promoting the temperature of its middle layer and irradiated surface. In the newly proposed wall, there was no thermal-stable layer observed, resulting in a minimum temperature rise of $1.34^{\circ} \mathrm{C}$. The proposed solution also enhanced the wall's heat storage capacity by $35.27 \%-47.89 \%$ and the heat release capacity by $49.93 \%-60.21 \%$, resulting in an average increase of indoor air temperature, daily effective accumulative temperature and soil temperature by $1.58-4.16^{\circ} \mathrm{C}, 33.33 \%-55.06 \%$ and $0.53-1.09^{\circ} \mathrm{C}$, respectively. The plant height, stem diameter and fruit yield have been increased by $30 \%, 25 \%$ and $28 \%$, respectively.
\end{abstract}

Keywords: Solar greenhouse; Phase change material; Ventilation wall; thermal performance; Experimental study

\section{Nomenclature}

Symbols

c Specific heat capacity, $\mathrm{J} /\left(\mathrm{kg}^{\circ} \mathrm{C}\right)$

d Equivalent diameter, $\mathrm{m}$

DEAT Daily effective accumulative temperature, ${ }^{\circ} \mathrm{Ch}$

*Corresponding author. chenchao@bjut.edu.cn (C. Chen), linghaoshu@163.com (H. Ling). 


$\begin{array}{ll}f & \text { Friction coefficient } \\ I & \text { Solar radiation, } \mathrm{W} / \mathrm{m}^{2} \\ k & \text { Thermal conductivity, } \mathrm{W} /\left(\mathrm{m}^{2 \circ} \mathrm{C}\right) \\ \mathrm{Pr} & \text { Prandtl number } \\ Q & \text { Heat capacity, } \mathrm{J} / \mathrm{m}^{3} \\ r & \text { Absolute roughness, } \mathrm{m} \\ \mathrm{St} & \text { Standon number } \\ t & \text { Temperature, }{ }^{\circ} \mathrm{C} \\ v & \text { Velocity, } \mathrm{m} / \mathrm{s} \\ x & \text { Length, } \mathrm{m} \\ y & \text { Thickness, } \mathrm{m}\end{array}$

Greek letters

$\begin{array}{ll}\alpha & \text { Natural convection heat transfer coefficient, } \mathrm{W} /\left(\mathrm{m}^{2 \circ} \mathrm{C}\right) \\ \beta & \text { Forced convection heat transfer coefficient, } \mathrm{W} /\left(\mathrm{m}^{2 \circ} \mathrm{C}\right) \\ \varepsilon & \text { Solar absorptance, } \% \\ \zeta & \text { Open }(1) \text { and close }(0) \text { status } \\ \rho & \text { Density, } \mathrm{kg} / \mathrm{m}^{3} \\ \tau & \text { Time, } \mathrm{s} \\ \chi & \text { Solar transmittance, } \%\end{array}$

\section{Subscripts}

Acse East surface of air channel

Acsn South surface of air channel

Acss North surface of air channel

air Hot air inside the air channel

Br1 Hollow block

$\mathrm{Br} 2 \quad$ Solid block

fl Front roof

hsc Heat storage capacity

hrc Heat release capacity

id Indoor

In Polystyrene boards

min Minimum

od Outdoor

PCM PCM wallboards

$v \quad$ Vertical

w Wall

Wh Whole wall

\section{Introduction}

With the continuous expansion of population, increasing food production using advanced technologies has become a crucial research area [1-4]. Solar greenhouses are 
advanced agricultural buildings, popularly used to provide suitable thermal environment for off-season crops [5-7]. Their indoor thermal environment is mainly affected by the thermal performance of the building envelops, especially the north wall in northern hemisphere [8-10]. Enhancing the thermal performance of the wall can increase the indoor air temperature by up to $10^{\circ} \mathrm{C}$, fulfilling $35 \%-82 \%$ heating requirement depending on their locations $[11,12]$.

A number of studies have confirmed that using phase change material (PCM) in the north wall of solar greenhouses in northern hemisphere was an efficient way to improve their indoor thermal environment [13-15], due to its high heat storage density and nearly isothermal nature during the charge/discharge process [16-18]. Guarino et al. [19] used PCM at the inner layer of walls in solaria in a cold climate. Based on experimental results, they found that the PCM wall provided benefits through the whole year, due to the PCM's ability of storing solar radiation during the daytime and releasing the stored heat during the nighttime, which could be up to 6-8 h after sunset. Berroug et al. [20] used $\mathrm{CaCl}_{2} \cdot 6 \mathrm{H}_{2} \mathrm{O}$ as PCM and analyzed its effectiveness on the north wall of solar greenhouses, based on simulation. The study found that the north wall with PCM performed a higher heat storage potential, leading to an increase of indoor air temperature by $6-12^{\circ} \mathrm{C}$. Najjar and Hasan [21] developed a mathematical model for a greenhouse with PCM. Prediction results indicated that PCM could decrease the swing of indoor air temperature during the $24 \mathrm{~h}$ period by $3-5^{\circ} \mathrm{C}$. Guan et al. [22] developed a three-layer wall with PCM for solar greenhouses. By doing this, the effective heat storage capacity of the wall was increased by $12.2 \%-14.0 \%$, and the indoor air temperature at night was raised by $2.5^{\circ} \mathrm{C}$. In a previous study carried out by the authors of this paper [5], the thermal performance of walls with and without PCM was evaluated in a solar greenhouse, using both experimental and numerical methods. The study demonstrated a positive contribution to operative temperature, with a maximum temperature increase of $1.1^{\circ} \mathrm{C}$.

Although using PCM in walls of solar greenhouses can promote indoor thermal environment, they absorb and accumulate solar energy touching their irradiated surfaces in a passive way $[23,24]$. The stored heat would then be transferred into middle layer through heat conduction $[25,26]$. Due to the limited thermal conductivity of PCM, the heat could not be efficiently transferred to the middle layer of the walls, forming a thermal-stable layer inside the walls. The existence of this thermal-stable layer greatly decreases the wall's heat storage capacity. In previous studies carried out by the authors [27, 28], PCM wallboards with a thickness of $200 \mathrm{~mm}$ have been incorporated into the standard greenhouse north wall, which had a thickness of $850 \mathrm{~mm}$. Its temperature distribution was then calculated using a one-dimensional unsteady numerical heat transfer model, with calculation results shown in Figure 1. The results reflected that solar energy received by the greenhouse had little influence on PCM after a depth of $150 \mathrm{~mm}$. For the experimental wall, the thickness of the thermal-stable layer inside the wall has reached $750 \mathrm{~mm}$. Guan et al. [22] also suggested that for a three-layer PCM wall with a thickness of $900 \mathrm{~mm}$, the part that was affected by solar gains was only about $300 \mathrm{~mm}$, 
and the thermal-stable layer had a thickness of 400mm. Wang et al. [29] carried out a numerical study to predict the temperature distribution inside the north wall with an average thickness of $3.0 \mathrm{~m}$. Based on the results, they suggested that the temperature of the middle part of walls, especially between $0.7 \mathrm{~m}$ and $2.3 \mathrm{~m}$, would hardly change.

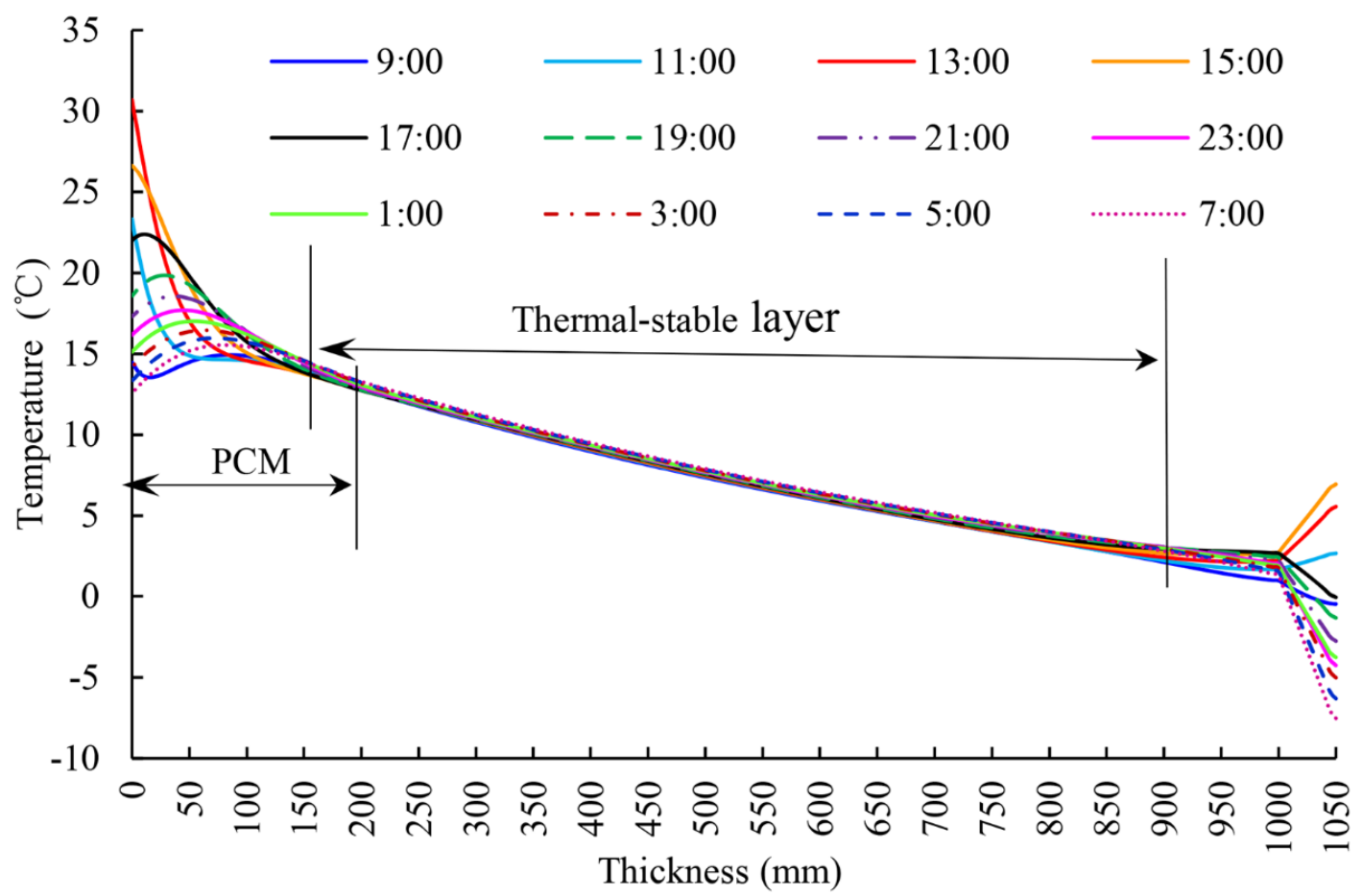

Figure 1: Calculated temperature distributions of a PCM wall.

To improve the temperature of the middle layer and promote the heat storage capacity of north walls in solar greenhouses, an active method is highly required, by using ventilation to heat the middle layers effectively. Some researchers have explored the effectiveness of this method on promoting building performance [30, 31]. Evola et al. [32] carried out a numerical study on a PCM wall, and found that the daily storage efficiency of the PCM wall could be improved by $78.2 \%$ when adding a ventilated cavity, with an increased thermal comfort frequency to $91.52 \%$. El Mankib et al. [33] predicted the thermal behaviors of an active multi-layer ventilation wall with PCM using simulation. According to the prediction results, a maximum saving of $95 \%$ for heating could be achieved when using the ventilated wall with PCM. Diarce et al. [34, 35] designed a PCM wall with a ventilated active façade and carried out an experimental study to identify its thermal performance. Their results showed that about $10 \%-12 \%$ incident radiation could be stored by the ventilated active facade, with an increase of average indoor temperature of $1.1^{\circ} \mathrm{C}$.

The above studies, however, focused on residential applications, rather than solar greenhouses. Comparing to residential buildings, solar greenhouses can obtain more solar energy during the daytime due to their architectural and structural characteristics. Therefore, an investigation on using ventilated PCM walls in solar greenhouses should 
be valuable and necessary. Additionally, existing studies focused on the effectiveness of this active method on the overall performance of the wall, hence neglecting its contribution to the wall's middle layer and occupants. This is not good for a deep understanding of the method's contribution and exploring future improvement.

To fill these gaps, this paper introduces results from a comparative study carried out in Urumchi, China, in which important parameters, namely, wall temperature, indoor air temperature, soil temperature, crop growth and fruit yield, have been monitored continuously in two parts of one solar greenhouse, one part with a ventilated north wall and another part with a conventional north wall. Additionally, some crucial indicators, namely, average temperature distribution and heat storage/release capacity of walls, have been calculated using an established two-dimensional unsteady numerical heat transfer model in this study. Both monitored and numerical data have been critically analyzed to justify the contribution of the active method to promoting the solar greenhouse's thermal performance.

\section{Materials and methods}

\subsection{The proposed active-passive ventilation wall with PCM}

For a more effective use of ventilation to heat the middle layer of walls in solar greenhouses, hence promoting their heat storage capacity, an active-passive ventilation wall with PCM has been developed in this study, as shown in Figure 2. In northern hemisphere, solar energy could go into the solar greenhouse and irradiate directly on the inner surface of the north wall during the daytime. Therefore, a PCM layer has been widely used as the most inner layer of the proposed wall to store solar energy during the daytime, considered as a passive method. The middle layer was composed of hollow blocks and solid blocks. The hollow blocks have been used to form several vertical parallel air channels, which were connected to air pipes from solar collectors installed on the top of the proposed wall. During the daytime, solar collectors absorbed solar energy to heat the air inside the air pipes, as shown in Figure 2a. The heated air by solar collectors was then sent into these air channels to increase the temperature of the middle layer, hence promoting its heat storage capacity using this active method. The most outer layer of the wall was built with insulation material to reduce the heat loss to the outdoor environment. 
(a)
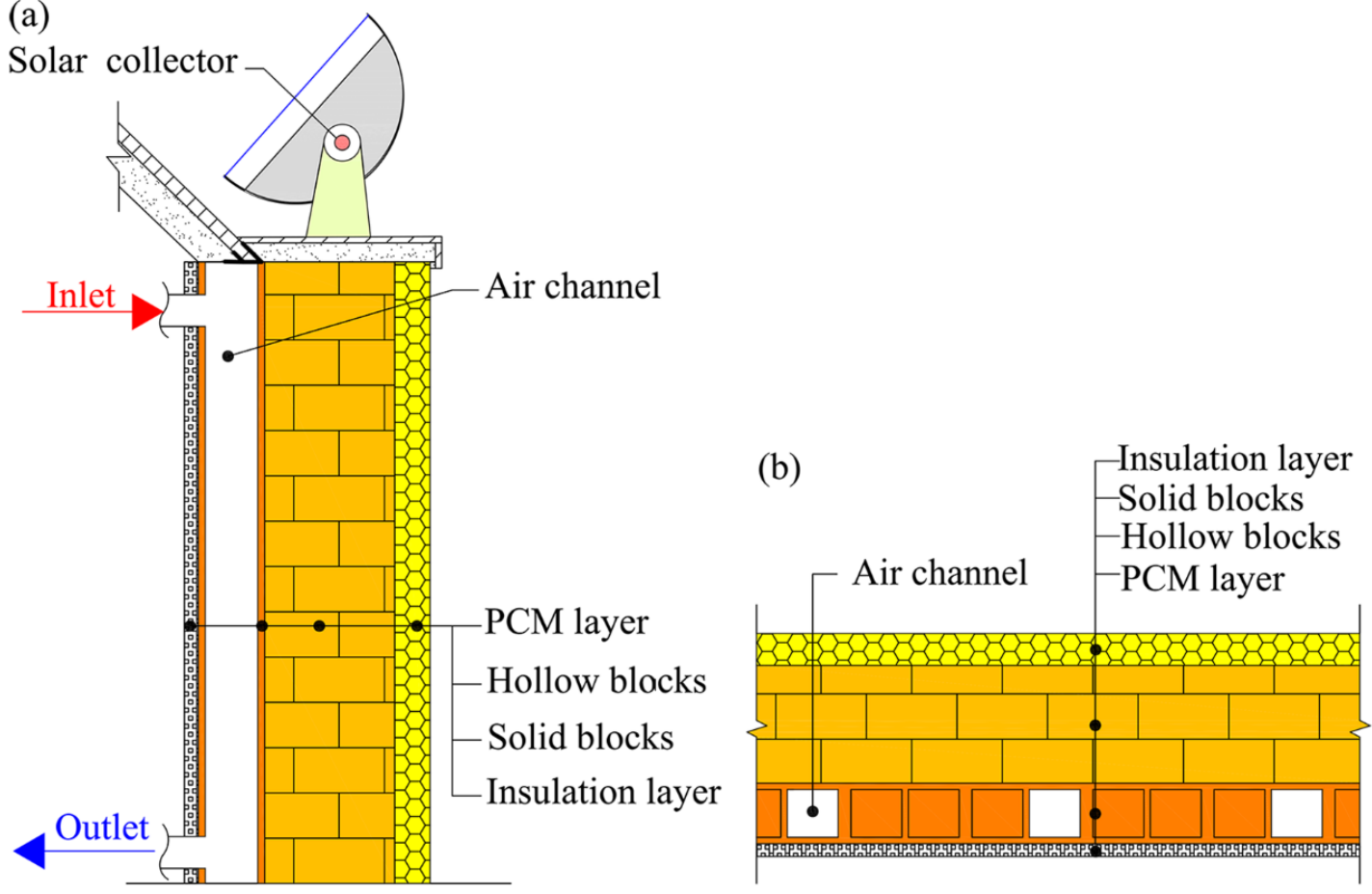

Figure 2: Schematic diagram of the active-passive ventilation wall with PCM: (a) Vertical section; (b) Horizontal section.

\subsection{Experimental installation and test}

\subsubsection{Experimental setup}

The solar greenhouse used in this study was located in Urumchi $\left(43.63^{\circ} \mathrm{N}, 87.23^{\circ} \mathrm{E}\right)$, China. It faced south and extended alongside the east-west direction, with interior dimensions of $50 \mathrm{~m}$ (length) $\times 8 \mathrm{~m}$ (width), as shown in Figure 3a. It was formed with a north wall, a back roof and a front roof. The front roof was built with a $0.12 \mathrm{~mm}$ thick transparent ethylene vinyl-acetate copolymer film, allowing solar energy to penetrate directly into the solar greenhouse during the daytime (10:00 to 19:00). A water-proof felt with a thickness of $20 \mathrm{~mm}$ was laid over the film for thermal insulation during the nighttime (19:00 to 10:00 day+1). On the top of the front roof, there was a bar vent opened between 13:30 and 15:30 to release excessive heat and humidity.

In order to demonstrate the effectiveness of the proposed wall regarding to thermal performance improvement, a comparative study has been carried out. In the study, the experimental solar greenhouse was separated into two identical sections using a polystyrene board with a thickness of $0.1 \mathrm{~m}$, as shown in Figure 3a. For comparison, one section was built with the proposed wall, and another section was built with a conventional wall, as shown in Figures $3 b$ and $3 c$. The proposed wall was made of $0.1 \mathrm{~m}$ thick polystyrene boards, $0.37 \mathrm{~m}$ thick solid blocks, $0.19 \mathrm{~m}$ thick hollow blocks and $0.04 \mathrm{~m}$ thick PCM wallboards, from outside to inside. There was a vertical air channel with a dimension of $0.16 \mathrm{~m}$ (length) $\times 0.15 \mathrm{~mm}$ (width) in the middle of each hollow 
block, so there were in total thirty parallel air channels alongside the length of the proposed wall, with a gap between air channels of $800 \mathrm{~mm}$, as shown in Figure 3c. The air sent to these air channels was heated by a group of trough solar collectors, with a dimension of $16 \mathrm{~m}$ (length) $\times 0.6 \mathrm{~m}$ (width) and running between 11:00 and 17:00. The conventional wall used for comparison had the same construction, but with no PCM wallboards, air channels and solar collectors, which is shown in Figure 3e.
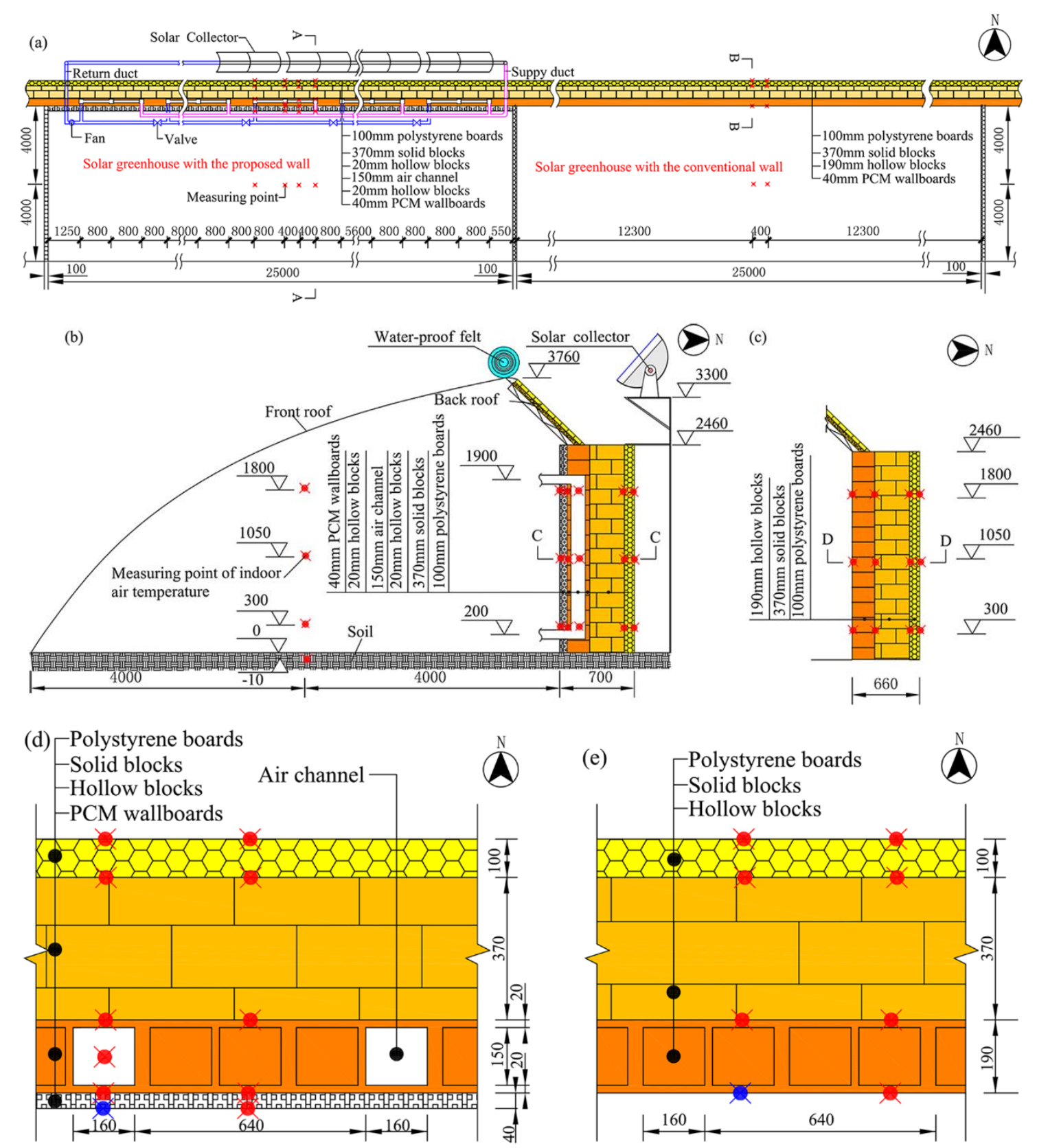

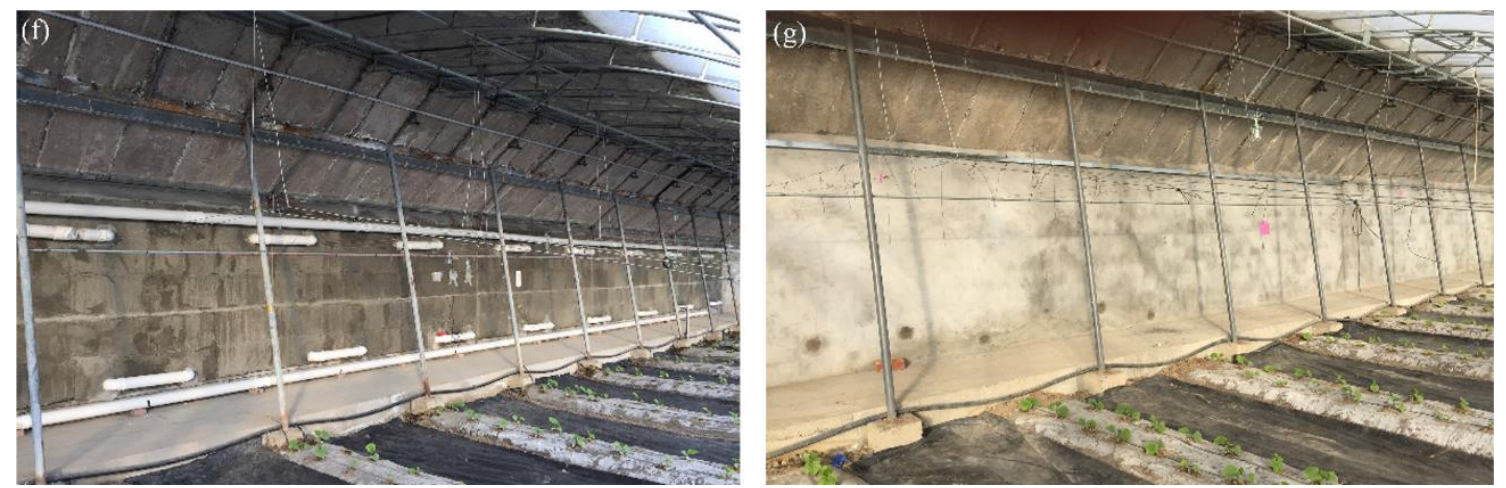

Figure 3: Schematic diagrams of the experimental greenhouse: (a) Horizontal section; (b) A-A section; (c) B-B section; (d) C-C section; (e) D-D section; (f) Section with the proposed wall; (g) Section with the conventional wall.

The PCM wallboard used in this study was made of a mixture of cement mortar and paraffin-based PCM, with a mass ratio of 44.3\%:55.7\%. The paraffin-based PCM was a kind of shape-stablilised PCM, consisting of paraffin wax, high density polyethylene and expanded graphite [36]. Figure 4 depicts its Differential Scanning Calorimetry (DSC) curve, based on a sample mass of $14.291 \mathrm{mg}$, when heated from $-15^{\circ} \mathrm{C}$ to $55^{\circ} \mathrm{C}$ at a temperature rising rate of $1{ }^{\circ} \mathrm{C} / \mathrm{min}$. The curve reflects that the phase change temperature of the PCM wallboard was ranging between $10.5^{\circ} \mathrm{C}$ and $24.5^{\circ} \mathrm{C}$, with a peak phase change temperature of $22.5^{\circ} \mathrm{C}$ and a heat of fusion of $92.0 \mathrm{~kJ} / \mathrm{kg}$. Some important thermophysical characteristics of the materials used in this study are available in Table 1 .

Table 1. Thermophysical parameters of materials used in this study.

\begin{tabular}{|c|c|c|c|c|c|c|c|}
\hline Material & $\begin{array}{l}\text { Thermal } \\
\text { conductivity } \\
\mathrm{W} /\left(\mathrm{m}^{\circ} \mathrm{C}\right)\end{array}$ & $\begin{array}{l}\text { Specific } \\
\text { heat } \\
\mathrm{kJ} /\left(\mathrm{kg}^{\circ} \mathrm{C}\right)\end{array}$ & $\begin{array}{l}\text { Density } \\
\mathrm{kg} / \mathrm{m}^{3}\end{array}$ & $\begin{array}{l}\text { Solar } \\
\text { absorptance } \\
\%\end{array}$ & $\begin{array}{l}\text { Absolute } \\
\text { roughness } \\
\mathrm{mm}\end{array}$ & $\begin{array}{l}\text { Solar } \\
\text { transmittance } \\
\%\end{array}$ & $\operatorname{Pr}$ \\
\hline PCM wallboards & 0.56 & Fig. 4 & 900 & 86 & - & - & - \\
\hline Hollow blocks & 0.93 & 1.05 & 2400 & - & 0.15 & - & - \\
\hline Solid blocks & 0.81 & 1.05 & 1800 & - & - & - & - \\
\hline Polystyrene boards & 0.04 & 1.38 & 30 & - & - & - & - \\
\hline Film & 0.76 & - & - & - & - & 58 & - \\
\hline Felt & 0.06 & - & - & - & - & - & - \\
\hline Air & 0.03 & 1.01 & 1.13 & - & - & - & 0.70 \\
\hline Soil & 1.41 & 1.84 & 1850 & 65 & - & - & - \\
\hline
\end{tabular}




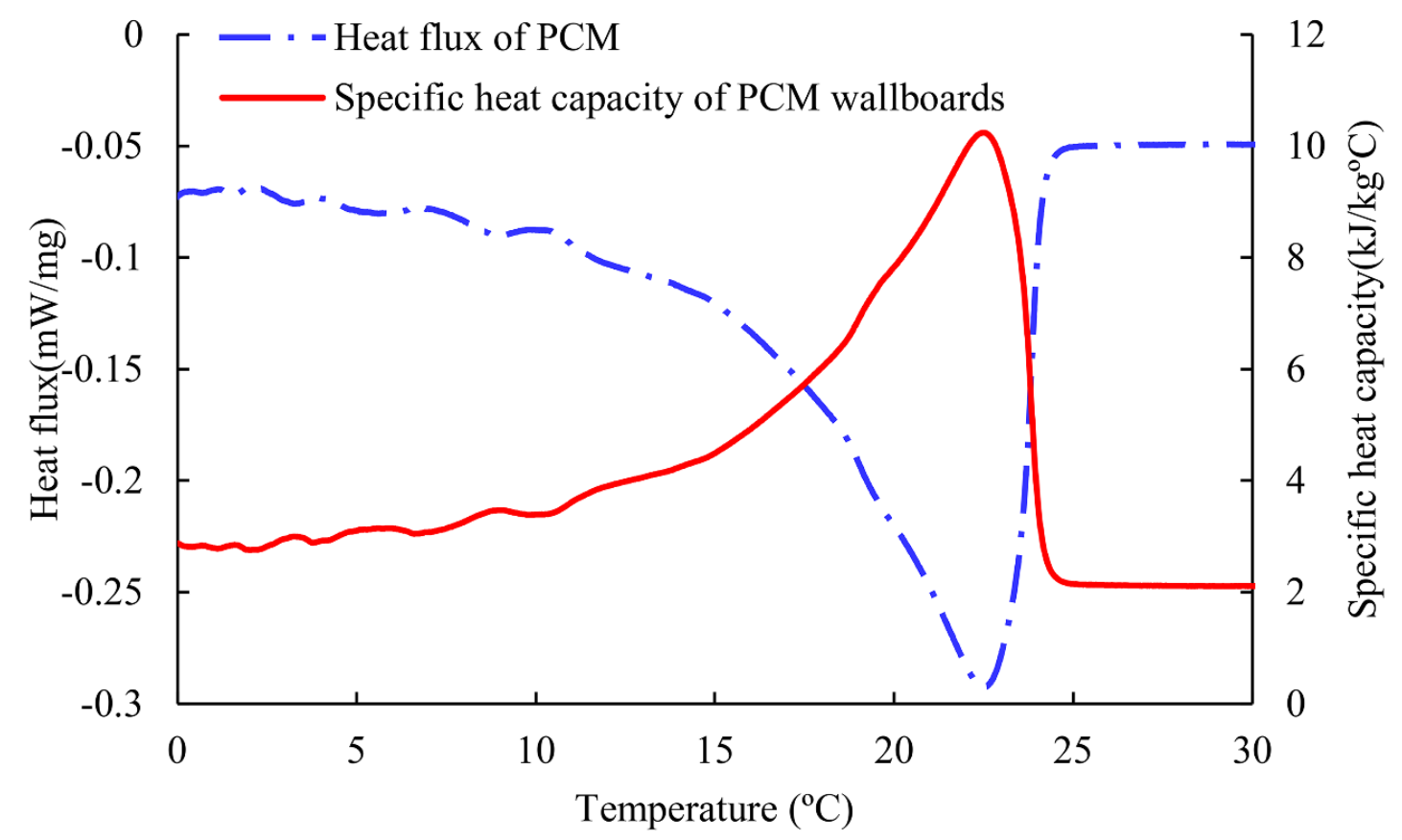

Figure 4: The DSC curve of the PCM and equivalent specific heat capacity of the PCM wallboard.

\subsubsection{Data collection}

During the experiment, several important parameters were measured, including solar radiation, outdoor air temperature, indoor air temperature, wall temperature at different positions, air temperature and velocity inside the air channel, soil temperature at $10 \mathrm{~cm}$ depth, plant height, stem diameter and fruit yield of crops.

Solar radiation and outdoor air temperature were monitored by a PC-3 portable weather station, with accuracies of $\pm 10 \mathrm{~W} / \mathrm{m}^{2}$ and $\pm 0.4^{\circ} \mathrm{C}$, respectively. A data acquisition system including one hundred and seventeen T-type thermocouples (accuracy of $\pm 0.5^{\circ} \mathrm{C}$ ) was used to monitor and record indoor air temperature, wall temperature at different positions, air temperature inside the air channel and soil temperature at $10 \mathrm{~cm}$ depth. Figures $3 \mathrm{a}-3 \mathrm{e}$ show the positions of these temperature measurements, and Table 2 lists important information. Air velocity inside the air channel was collected and recorded at a height of $1.05 \mathrm{~m}$ by a hot-wired anemometer, with a measurement error lower than $0.01 \mathrm{~m} / \mathrm{s}$. The measurement interval of the aforementioned parameters has been chosen as five minutes.

Table 2. The information of the temperature measurements.

\begin{tabular}{llllll}
\hline Parameter & Section & $\begin{array}{l}\text { Total number of } \\
\text { thermocouples }\end{array}$ & $\begin{array}{l}\text { Location } \\
(\mathrm{m}) \\
\text { Length }\end{array}$ & Width & Height \\
\hline \multirow{2}{*}{$\begin{array}{l}\text { Indoor air } \\
\text { temperature }\end{array}$} & The proposed & \multirow{2}{*}{12} & $13.25,14.05$, & 4.00 & $0.30,1.05$, \\
& wall & & $14.45,14.85$ & & 1.80 \\
& The conventional & 6 & $12.30,12.70$ & 4.00 & $0.30,1.05$,
\end{tabular}


wall

\begin{tabular}{|c|c|c|c|c|c|}
\hline \multirow{2}{*}{$\begin{array}{l}\text { Wall } \\
\text { temperature }\end{array}$} & $\begin{array}{l}\text { The proposed } \\
\text { wall }\end{array}$ & 60 & $\begin{array}{l}13.25,14.05 \\
14.45,14.85\end{array}$ & $\begin{array}{l}0.00,-0.04, \\
-0.23,-0.60, \\
-0.70\end{array}$ & $\begin{array}{l}0.30,1.05, \\
1.80\end{array}$ \\
\hline & $\begin{array}{l}\text { The conventional } \\
\text { wall }\end{array}$ & 24 & $12.30,12.70$ & $\begin{array}{l}0.00,-0.19 \\
-0.56,-0.66\end{array}$ & $\begin{array}{l}0.30,1.05, \\
1.80\end{array}$ \\
\hline $\begin{array}{l}\text { Hot air } \\
\text { temperature }\end{array}$ & $\begin{array}{l}\text { The proposed } \\
\text { wall }\end{array}$ & 9 & $\begin{array}{l}13.25,14.05 \\
14.85\end{array}$ & -0.135 & $\begin{array}{l}0.30,1.05, \\
1.80\end{array}$ \\
\hline \multirow{2}{*}{$\begin{array}{l}\text { Soil } \\
\text { temperature }\end{array}$} & $\begin{array}{l}\text { The proposed } \\
\text { wall }\end{array}$ & 4 & $\begin{array}{l}13.25,14.05 \\
14.45,14.85\end{array}$ & 4.00 & -0.01 \\
\hline & $\begin{array}{l}\text { The conventional } \\
\text { wall }\end{array}$ & 2 & $12.30,12.70$ & 4.00 & -0.01 \\
\hline
\end{tabular}

To illustrate the effectiveness of the proposed wall on crops' growing, four hundred and eighteen tomato seedlings with identical characteristic and growth status were evenly planted in the two parts of the solar greenhouse. A ruler with an accuracy of $\pm 0.5 \mathrm{~mm}$ was used to measure the height of the crops, and a vernier caliper with an accuracy of $\pm 0.05 \mathrm{~mm}$ was used to monitor their stem diameter. The measurement interval of both parameters was set as ten days. After tomatoes became mature, they were weighed by an electronic balance with accuracy of $\pm 0.1 \mathrm{~g}$.

\subsubsection{Experimental conditions}

During the experiment, the solar greenhouse was monitored and recorded continuously, between $19^{\text {th }}$ November, 2015 and $4^{\text {th }}$ July, 2016, lasting for 229 days. The weather condition is depicted in Figure 5. During the whole monitoring period, the daily maximum solar radiation changed between $148 \mathrm{~W} / \mathrm{m}^{2}$ and $954 \mathrm{~W} / \mathrm{m}^{2}$, and the outdoor air temperature varied between $-19.0^{\circ} \mathrm{C}$ and $35.0{ }^{\circ} \mathrm{C}$. The later analysis was focusing on the data collected between 10:00 on February 27, 2016 and 10:00 on March 1, 2016, and the outdoor air temperature and solar radiation of this period are described in Figure 6. The analyzing dates selected were all sunny days (with sufficient solar radiation), with outdoor air temperature varying between $-2.2^{\circ} \mathrm{C}$ and $12.9^{\circ} \mathrm{C}$ and a maximum solar radiation of $655 \mathrm{~W} / \mathrm{m}^{2}$. 


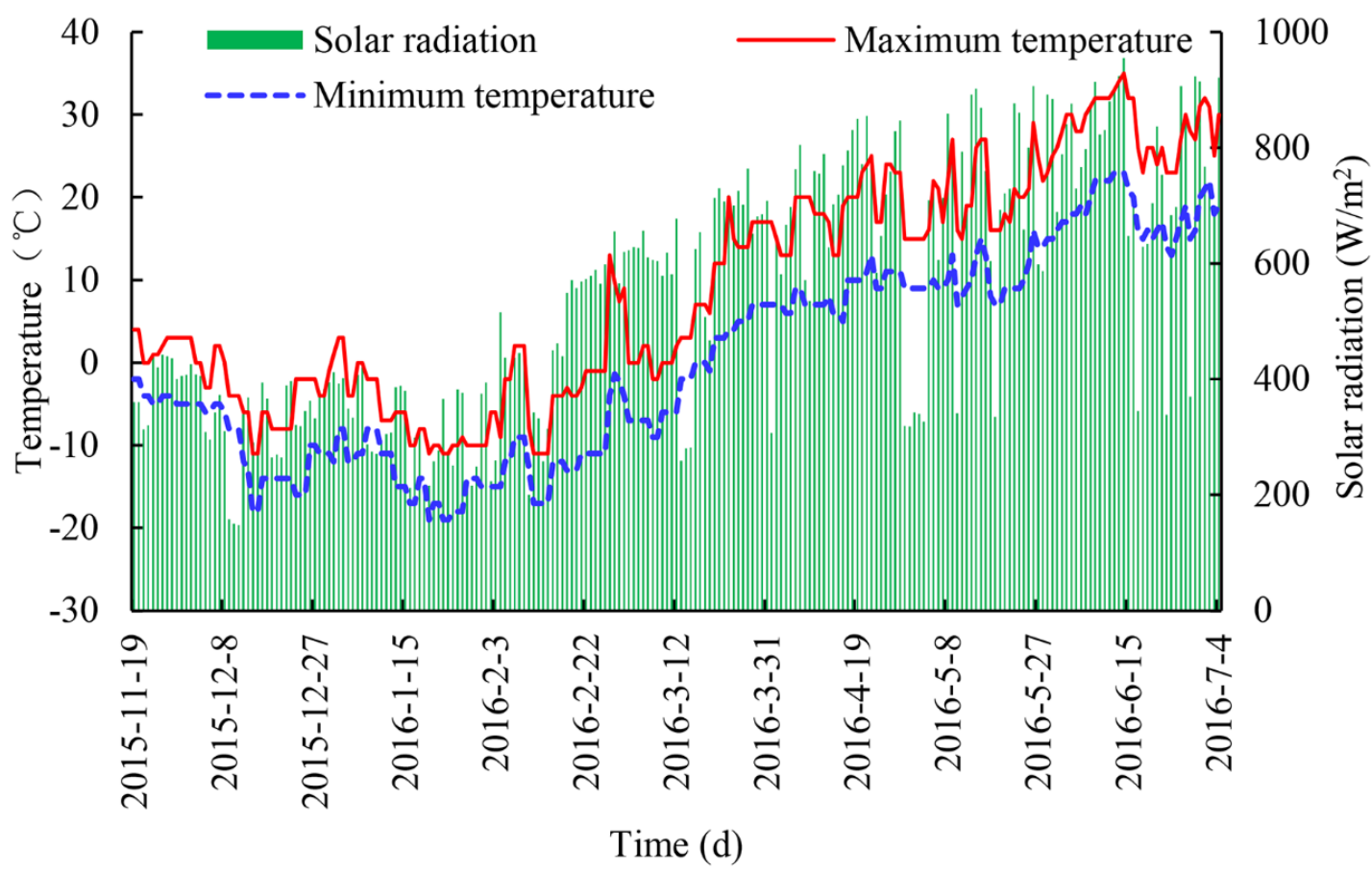

Figure 5: Weather condition of the whole monitoring period.

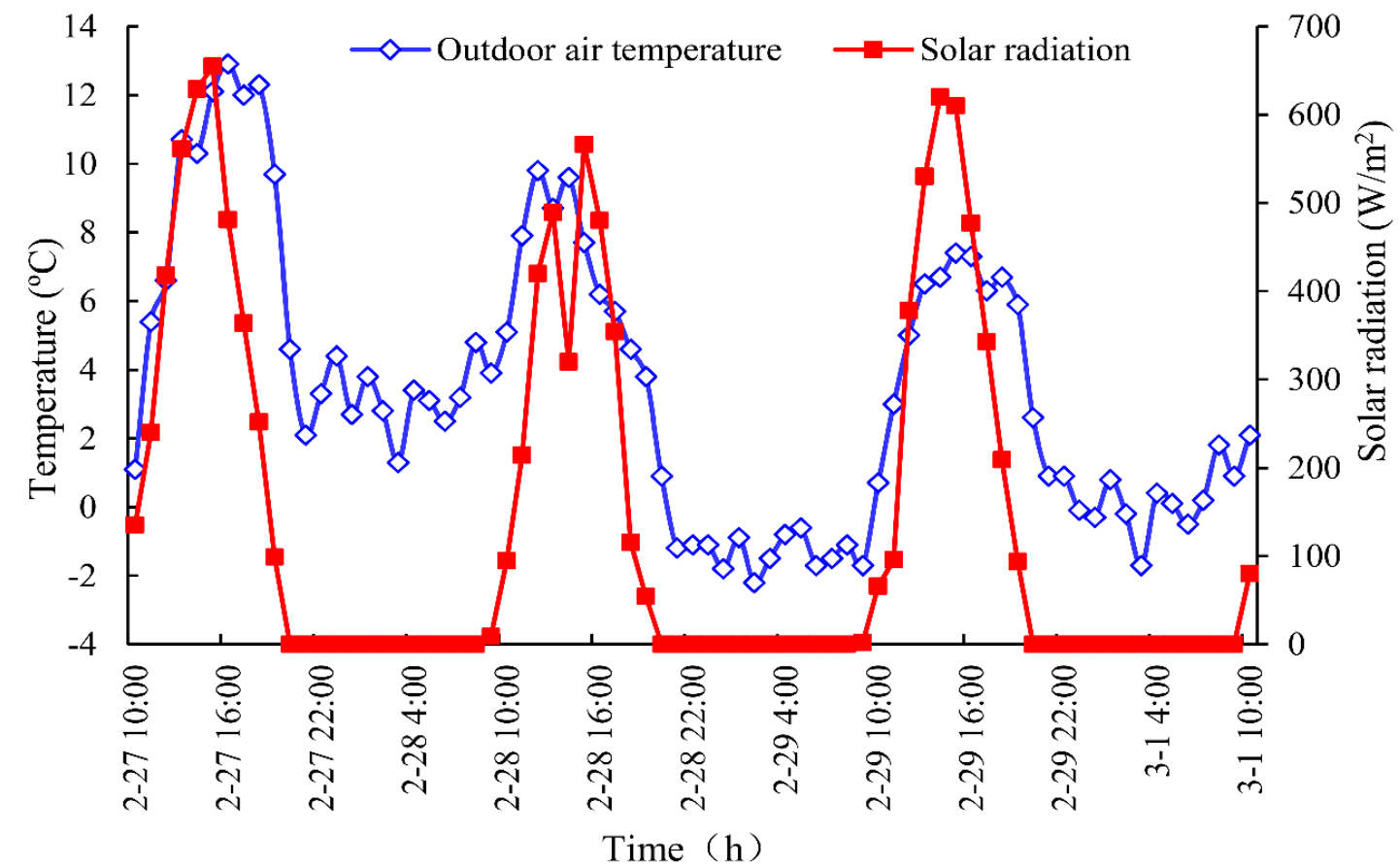

Figure 6: Weather condition during the investigating period.

\subsection{Performance indicators}

\subsubsection{Irradiated surface temperature of the wall}

During the daytime, the front roof is made of a transparent film to enable solar energy to warm the wall's irradiated surface [37]. Because PCM is in the irradiated layer of the proposed wall, its thermal performance can be improved by keeping the wall's most 
inner surface at a higher temperature than for the conventional wall. Therefore, the irradiated surface temperature of the proposed wall and the conventional wall is chosen to indicate the effectiveness of PCM on improving the thermal performance of walls in solar greenhouses.

When the heated air moves through the air channels, there will be a strong convective heat transfer with the inner surface of the air channels. Therefore, some heat has been transferred to the irradiated surface of the proposed wall by conduction [27]. Because of this process, the irradiated surface temperature of the proposed wall with and without air channel has been chosen separately to reflect the effect of ventilation on the thermal performance of the proposed wall.

\subsubsection{Temperature distribution of the wall}

During the daytime, heat obtained by the irradiated surface is transferred to the middle layer of the wall, and the temperature alongside the thickness will rise, hence increasing the wall's heat storage capacity. During the nighttime, heat of the irradiated surface of the wall is transferred to the indoor environment, so its temperature will go down. Due to the temperature difference, the heat stored in middle layer will be conducted to the irradiated surface, hence decreasing the wall's heat release capacity. Therefore, the temperature distribution of the wall has been chosen to be another performance indicator. Since the temperature at the same thickness of the proposed wall has a significant difference, the average temperature alongside the proposed wall has been calculated. Equation 1 defines the average temperature at any thickness $y_{0}$ of the proposed wall.

$$
\bar{t}_{w}\left(y_{0}\right)=\frac{\int_{0}^{x_{w h}} t_{w}\left(x, y_{0}\right) d x}{x_{w h}}
$$

\subsubsection{Heat storage/release capacity of the wall}

During the daytime, the wall has a significant temperature rise, and much heat is stored. The stored heat will have a positive impact on the heat release capacity and indoor air temperature during the nighttime. Therefore, the stored heat during the daytime is named as the heat storage capacity of the wall, which is defined as,

$$
Q_{h r s}=Q(19: 00)-Q(10: 00)
$$

During the nighttime, the heat release capacity of the wall is the only heat source of the indoor environment, and it contributes to keeping the indoor air temperature within a comfortable range. Therefore, it was considered as an important indicator and defined as, 


$$
Q_{h r c}=Q(19: 00)-Q(10: 00 \text { day }+1)
$$

2.3.4 Indoor air temperature, thermal discomfort time and daily effective accumulative temperature

Indoor air temperature is affected by the thermal performance of walls [38], and solar greenhouses are built for providing a comfortable thermal environment for off-season crops [39]. Therefore, indoor air temperature should be a key parameter. During the experiment, the average value of indoor air temperature at different heights and positions is calculated and compared to evaluate the effectiveness of the proposed wall on improving the indoor thermal comfort of solar greenhouses.

Every crop has a bearable minimum temperature. Crops can only grow healthily when the surrounding temperature is higher than this minimum temperature. Therefore, the evaluation of indoor air temperature should be based on the needs of crops. Both the thermal discomfort time and the daily effective accumulative temperature have been used as key indicators combining indoor air temperature and the need of crops [5]. The thermal discomfort time is defined as the time during which the indoor air temperature is lower than the bearable minimum temperature of the crop. The bearable minimum temperature of tomato seedlings used in this study has been suggested as $15^{\circ} \mathrm{C}$ when they begin to produce fruits [40]. The daily effective accumulative temperature is defined as the time integral of the positive difference between the hourly indoor air temperature and the bearable minimum temperature of crops, which is calculated by Equations 4 and 5. It is proportional to the daily maximum heat that crops may get from indoor air.

$$
\begin{gathered}
D E A T=\int_{24 h} \Delta t^{+}(\tau) \mathrm{d} \tau \\
\Delta t^{+}(\tau)=\left\{\begin{array}{ccc}
t_{i d}(\tau)-t_{\min } & \text { if } & t_{i d}(\tau) \geq t_{\min } \\
0 & \text { if } & t_{i d}(\tau)<t_{\min }
\end{array}\right.
\end{gathered}
$$

\subsubsection{Soil temperature}

Soil temperature is affected by both indoor air temperature and thermal performance of walls. It is also an important parameter affecting seed germination, seedling growth and root development. Therefore, it is chosen as a performance indicator as well.

\subsubsection{Plant height, stem diameter and fruit yield}

The plant height, stem diameter and fruit yield of crops are important indicators on their growth status. As a harvest of crops is the major purpose of using solar greenhouses, these parameters are important to be compared to reflect the performance of solar 
greenhouses.

\subsection{Analytical approach}

Although many performance indicators could be collected directly using specific devices, there were some, such as temperature distribution and heat storage/release capacity, that could not be measured directly. In this study, a two-dimensional unsteady numerical heat transfer model of the proposed wall has been developed to calculate these parameters.

Since there was a bigger structural change and heat transfer difference in the horizontal section of the proposed ventilated wall, its horizontal heat transfer progress was analyzed [27], which is shown in Figure 7. During the daytime, there was a comprehensive effect from solar radiation and natural convection on its irradiated surface, so the temperature of its irradiated surface will rise. When hot air passed through the surfaces of air channel, a forced convection occurred between the hot air and the channel inner surface, and its temperature will increase. Due to the temperature difference, the heat was conducted inside the proposed ventilated wall. Certainly, a natural convection also occurred on the outer surface. During the nighttime, the heat transfer progress was the same as the daytime, but without the effects from solar radiation and the hot air.

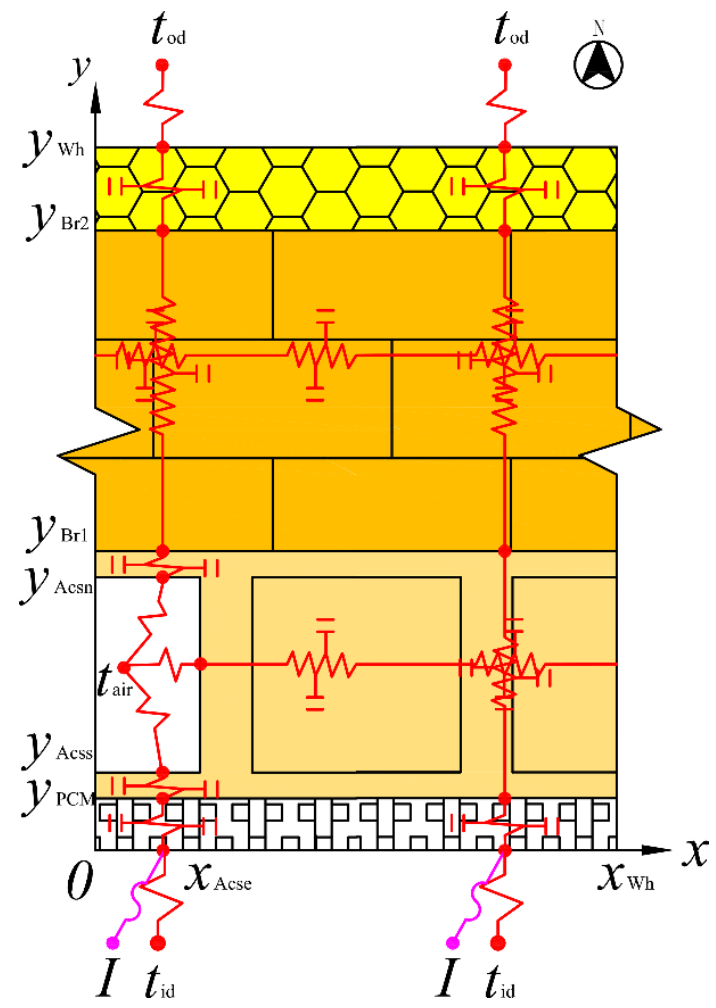

Figure 7: Heat transfer process of the proposed ventilated wall.

According to the heat transfer analysis, the two-dimensional heat transfer model of the proposed ventilated wall was defined by 


$$
\rho_{w} \frac{\partial\left(c_{w} t_{w}\right)}{\partial \tau}=k_{w}\left(\frac{\partial^{2} t_{w}}{\partial x^{2}}+\frac{\partial^{2} t_{w}}{\partial y^{2}}\right)
$$

with boundary conditions as,

$$
\begin{gathered}
k_{w} \frac{\partial t_{w}}{\partial y}=\alpha_{i d}\left(t_{w}-t_{i d}\right)+\chi \varsigma_{f l} \varepsilon_{P C M} I_{v} \text { at } 0 \leq x \leq x_{W h}, y=0 \\
k_{w} \frac{\partial t_{w}}{\partial y}=\beta\left(t_{\text {air }}-t_{w}\right) \text { at } 0 \leq x \leq x_{A c s e}, y=y_{P C M} \\
k_{w} \frac{\partial t_{w}}{\partial x}=\beta\left(t_{w}-t_{\text {air }}\right) \text { at } x=x_{A c s e}, y_{A c s s} \leq y \leq y_{A c s n} \\
k_{w} \frac{\partial t_{w}}{\partial y}=\beta\left(t_{\text {air }}-t_{w}\right) \text { at } 0 \leq x \leq x_{A c s e}, y=y_{A c s n} \\
k_{w} \frac{\partial t_{w}}{\partial y}=\alpha_{o d}\left(t_{o d}-t_{w}\right) \quad \text { at } 0 \leq x \leq x_{W h}, y=y_{W h} \\
\frac{\partial t_{w}}{\partial x}=0 \text { at } x=0,0 \leq y \leq y_{A c s s} \\
\frac{\partial t_{w}}{\partial x}=0 \text { at } x=0, y_{A c s n} \leq y \leq y_{W h} \\
\frac{\partial t_{w}}{\partial x}=0 \text { at } x=x_{W h}, 0 \leq y \leq y_{W h} \\
\end{gathered}
$$

where $\beta$ was the forced convection heat transfer coefficient. It was obtained by Equations $15-18$, as a result of the rough surfaces of the air channel [41].

$$
\begin{gathered}
d=\frac{2\left(2 x_{\text {Acse }}\right)\left(y_{\text {Acsn }}-y_{\text {Acss }}\right)}{\left(2 x_{\text {Acse }}\right)+\left(y_{\text {Acsn }}-y_{\text {Acss }}\right)} \\
f=\left[2 \lg \left(\frac{d}{2 r}\right)+1.74\right]^{-2} \\
S t=\frac{f}{8} \operatorname{Pr}^{-\frac{2}{3}} \\
\beta=S t \cdot \rho_{\text {air }} c_{\text {air }} v_{\text {air }}
\end{gathered}
$$


Since the proposed ventilated wall was constructed by different materials, its thermophysical properties were defined by Equation 19,

$$
\begin{cases}c_{w}=c_{P C M}, \rho_{w}=\rho_{P C M}, k_{w}=k_{P C M} & \text { if } 0 \leq x \leq x_{W h}, 0 \leq y \leq y_{P C M} \\ c_{w}=c_{B r 1}, \rho_{w}=\rho_{B r 1}, k_{w}=k_{B r 1} & \text { if } 0 \leq x \leq x_{W h}, y_{P C M}<y \leq y_{A c s s} \\ c_{w}=c_{B r 1}, \rho_{w}=\rho_{B r 1}, k_{w}=k_{B r 1} & \text { if } x_{A c s e} \leq x \leq x_{W h}, y_{A c s s}<y \leq y_{A c s n} \\ c_{w}=c_{B r 1}, \rho_{w}=\rho_{B r 1}, k_{w}=k_{B r 1} & \text { if } 0 \leq x \leq x_{W h}, y_{A c s n}<y \leq y_{B r 1} \\ c_{w}=c_{B r 2}, \rho_{w}=\rho_{B r 2}, k_{w}=k_{B r 2} & \text { if } 0 \leq x \leq x_{W h}, y_{B r 1}<y \leq y_{B r 2} \\ c_{w}=c_{I n}, \rho_{w}=\rho_{I n}, k_{w}=k_{I n} & \text { if } 0 \leq x \leq x_{W h}, y_{B r 2}<y \leq y_{W h}\end{cases}
$$

To solve the abovementioned model, the alternating direction implicit difference method [42] was employed to disperse these equations, and Matlab, a popular and powerful computational tool, was used to solve these discrete equations.

Based on the model introduced above, the accumulated heat storage capacity of the proposed wall was estimated by,

$$
Q(\tau)=\frac{\int_{0}^{x_{w h}} \int_{0}^{y_{w h}} \int_{t(0)}^{t(\tau)} \rho c\left(t_{w}\right) d t_{w} d x d y}{x_{w h} \cdot y_{w h}}
$$

The temperature distribution and the accumulated heat storage capacity of the conventional wall could be calculated by a one-dimensional unsteady numerical heat transfer model, which has been proposed and introduced in our previous studies $[5,28]$.

\section{Results and discussion}

\subsection{Irradiated surface temperature of the wall}

According to field measurements from a previous study [27], when the distance between the irradiated surface and air channel was bigger than $200 \mathrm{~mm}$, the effectiveness of ventilation in changing its temperature became relatively small. As shown in Figure 3d, a portion of the irradiated surface of the proposed wall was far away from air channels, with many measurement points over $400 \mathrm{~mm}$ away from the air channels. Therefore, the irradiated surface measured at these points could not be affected by the ventilation. Because of this, the contribution of PCM to the thermal performance of the walls in solar greenhouses could be evaluated by a comparison of the irradiated surface temperatures of the conventional wall and the proposed wall, when there is no air channels. Besides this, the effect of ventilation could be assessed by comparing the irradiated surface temperatures of the proposed wall with and without air channels. 


\subsubsection{Effect from PCM}

Figure 8 shows the irradiated surface temperatures of the conventional wall and the proposed wall without air channels. It indicates clearly that the irradiated surface temperature of both walls changed periodically, following a similar pattern. The irradiated surface temperature of the proposed wall was higher than that of the conventional wall at 10:00. Since solar radiation started to reach the irradiated surface of both walls after 10:00, they began to store heat and their temperature started to rise. However, the temperature rising rate of the proposed wall was less than that of the convectional wall, due to the higher heat storage density of PCM. The irradiated surface temperature of the conventional wall arrived at its peak at 16:00, and one hour earlier than the proposed wall, due to the heat storage by PCM. After then, the irradiated surface temperature of both walls started to drop, but the irradiated surface temperature of the proposed wall was always higher than that of the convectional wall. The temperature difference became larger with the change of time. During the nighttime, the maximum temperature difference between the two walls during the three days were $3.02^{\circ} \mathrm{C}, 3.74^{\circ} \mathrm{C}$ and $3.70^{\circ} \mathrm{C}$, respectively, and the average temperature difference were $2.01^{\circ} \mathrm{C}, 2.67^{\circ} \mathrm{C}$ and $2.66^{\circ} \mathrm{C}$, respectively. This analysis reflects that the PCM applied in the proposed wall helped to extend the heat storage time during the daytime and improve the irradiated surface temperature during the nighttime.

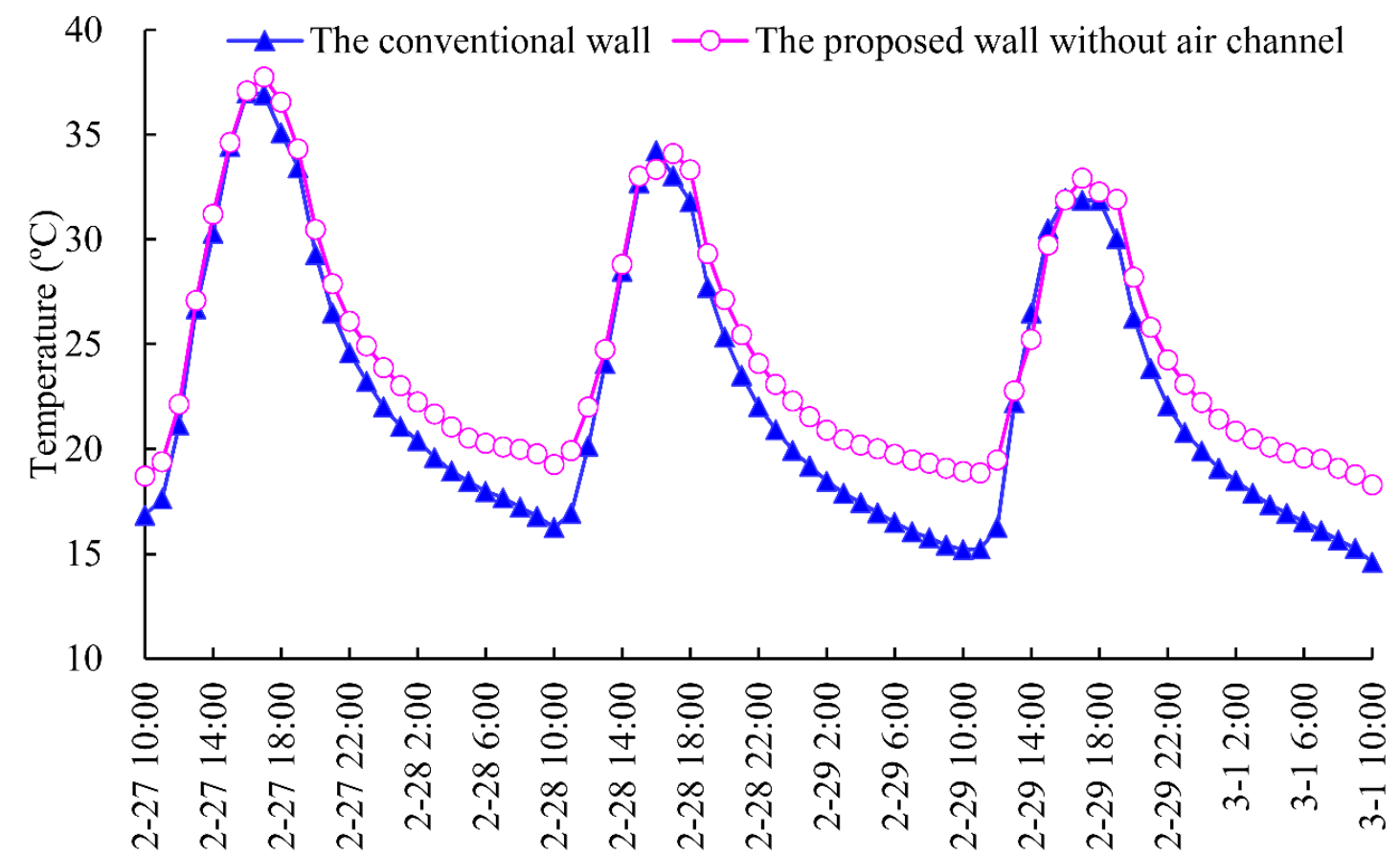

Time (h)

Figure 8: Irradiated surface temperature of both the conventional wall and the proposed wall without air channel.

\subsubsection{Effect from ventilation}

To assess the effect of ventilation inside the proposed wall on its irradiated surface 
temperature, the irradiated surface temperature of both proposed walls with and without air channels were measured and recorded, as depicted in Figure 9. It reflects the significant contribution of ventilation to enhancing the irradiated surface temperature during the daytime. It shows that the rise of the irradiated surface temperature of the proposed wall with air channels was higher than that without air channels, due to the heat provided by the ventilation through the air channels. The irradiated surface temperatures of both walls reached their peaks at 17:00. During the three testing days, the values of the proposed wall with air channels were $40.58^{\circ} \mathrm{C}, 36.61^{\circ} \mathrm{C}$ and $35.23^{\circ} \mathrm{C}$, respectively, over $2.2^{\circ} \mathrm{C}$ higher than those without air channels. During the period between 11:00 and 17:00, the average irradiated surface temperature of the proposed wall with air channels was also higher than that of without air channels, with differences of $1.64^{\circ} \mathrm{C}, 0.99^{\circ} \mathrm{C}$ and $0.98^{\circ} \mathrm{C}$, respectively. This is also due to the heat provided by the ventilation inside air channels.

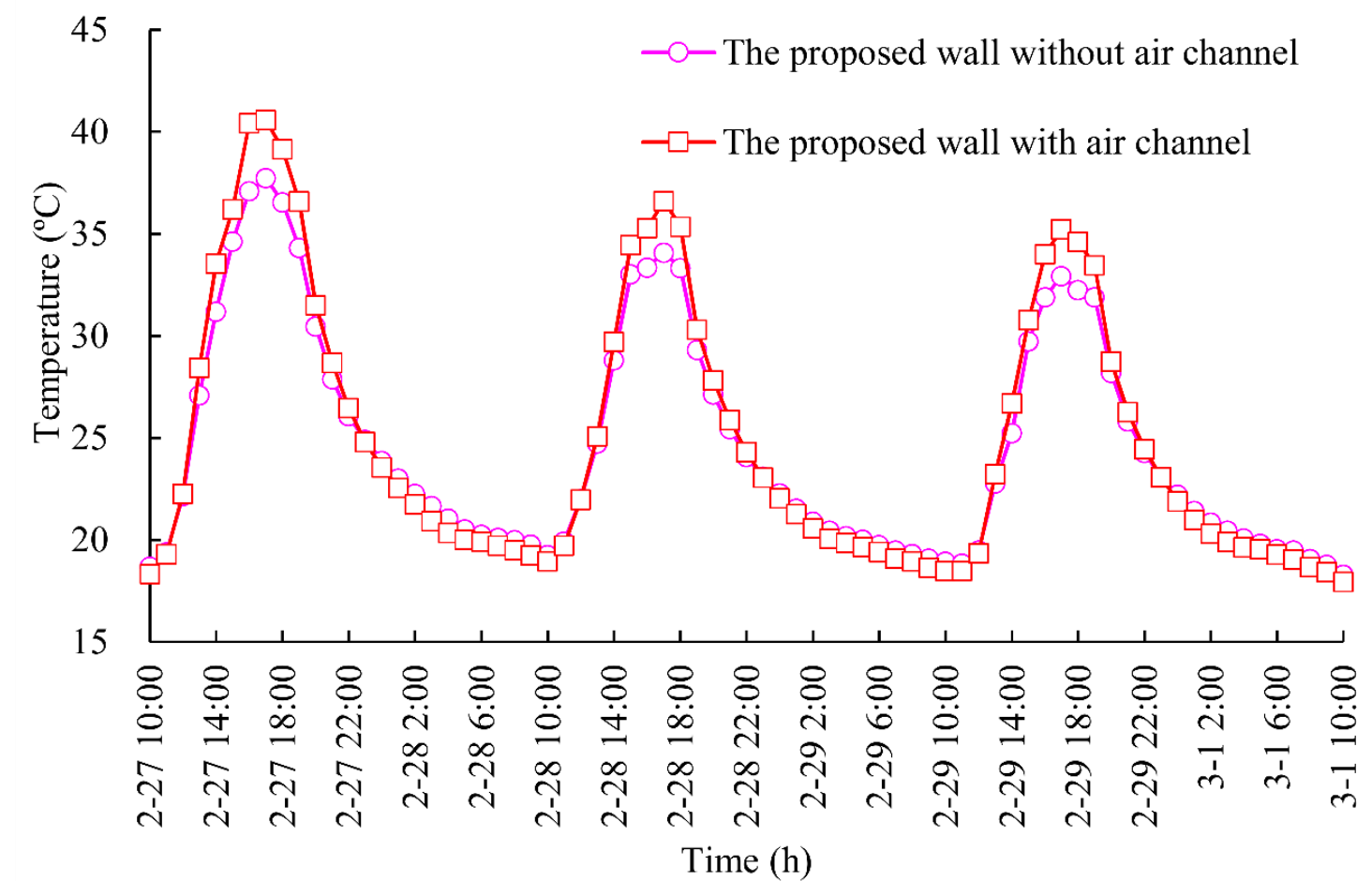

Figure 9: Irradiated surface temperature of the proposed wall with and without air channels.

\subsection{Temperature distribution}

To evaluate the effect of the proposed wall on the temperature of middle layer, the temperature distributions of the proposed and conventional walls at 10:00 and 19:00 on February 27 was calculated, which are compared in Figure 10. It shows that there was no thermal-stable layer inside the proposed wall, and the minimum temperature rise of the proposed wall was $1.34^{\circ} \mathrm{C}$. However, the minimum temperature rise of the conventional wall was $0^{\circ} \mathrm{C}$, and the temperature rise of the conventional wall in the depth of $220-420 \mathrm{~mm}$ was less $1^{\circ} \mathrm{C}$ [29], due to a thermal-stable layer with a thickness of $200 \mathrm{~mm}$. Additionally, the average temperature rise of the proposed wall was $5.6^{\circ} \mathrm{C}$, 
$1.0^{\circ} \mathrm{C}$ larger than that of the conventional wall. It means that the proposed wall had a larger heat storage capacity during the daytime, since the temperature rise had a positive influence on the heat storage capacity. Certainly, due to having a larger heat storage capacity during the daytime, the temperature of the proposed wall on 19:00 was also higher than that of the conventional wall, with the maximum and average temperature increase of $7.9^{\circ} \mathrm{C}$ and $4.3^{\circ} \mathrm{C}$, respectively. It also means that the proposed wall released more heat to the indoor environment during the nighttime, as a result of a higher temperature difference between them.

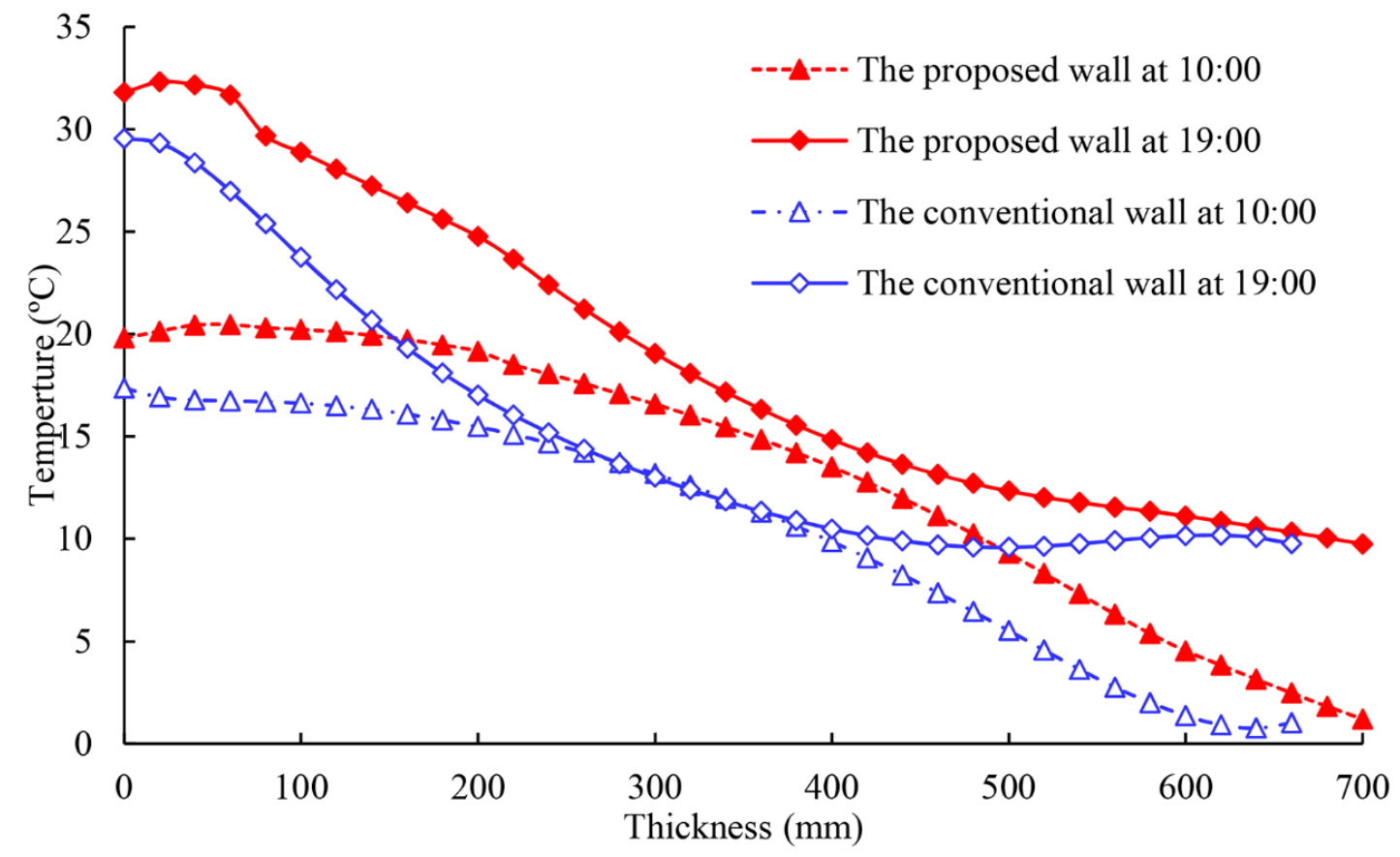

Figure 10: Temperature distribution of both the conventional wall and the proposed wall.

\subsection{Heat storage/release capacity}

The analysis result from Section 3.2 has reflected that the proposed wall should have a bigger heat storage/release capacity. To justify it, the heat storage and release capacities have been calculated, and the results are compared in Figure 11 for the proposed wall and the conventional wall. It can be seen that the calculated results are the same as the analysis above. During the investigating period, the heat storage capacity of the conventional wall were $7.52 \mathrm{MJ} / \mathrm{m}^{3}, 5.11 \mathrm{MJ} / \mathrm{m}^{3}$ and $6.11 \mathrm{MJ} / \mathrm{m}^{3}$, respectively. However, those values of the proposed wall were $11.12 \mathrm{MJ} / \mathrm{m}^{3}, 6.92 \mathrm{MJ} / \mathrm{m}^{3}$ and $8.89 \mathrm{MJ} / \mathrm{m}^{3}$, respectively, all were bigger than that of the conventional wall, with the increasing rate of $47.9 \%, 35.4 \%$ and $45.5 \%$, respectively. The heat release capacity of the proposed wall were $7.42 \mathrm{MJ} / \mathrm{m}^{3}, 9.22 \mathrm{MJ} / \mathrm{m}^{3}$ and $8.30 \mathrm{MJ} / \mathrm{m}^{3}$, respectively, which were $1.60,1.50$ and 1.51 times as higher as that of the conventional wall. Moreover, solar radiation had a positive contribution to the heat storage capacity of both walls, resulting in the highest heat storage capacity of both walls on $27^{\text {th }}$ February, and the lowest on $28^{\text {th }}$ February. The outdoor air temperature during the nighttime also had a positive effect on the heat release capacity. It can be noted that the heat storage capacity of both walls on $28^{\text {th }}$ 
February was less than their own heat release capacity. It means that both walls did not collect enough heat during the daytime, so the temperatures of both walls at the end of the night were less than the beginning of the day, as illustrated in Figures 8 and 9.

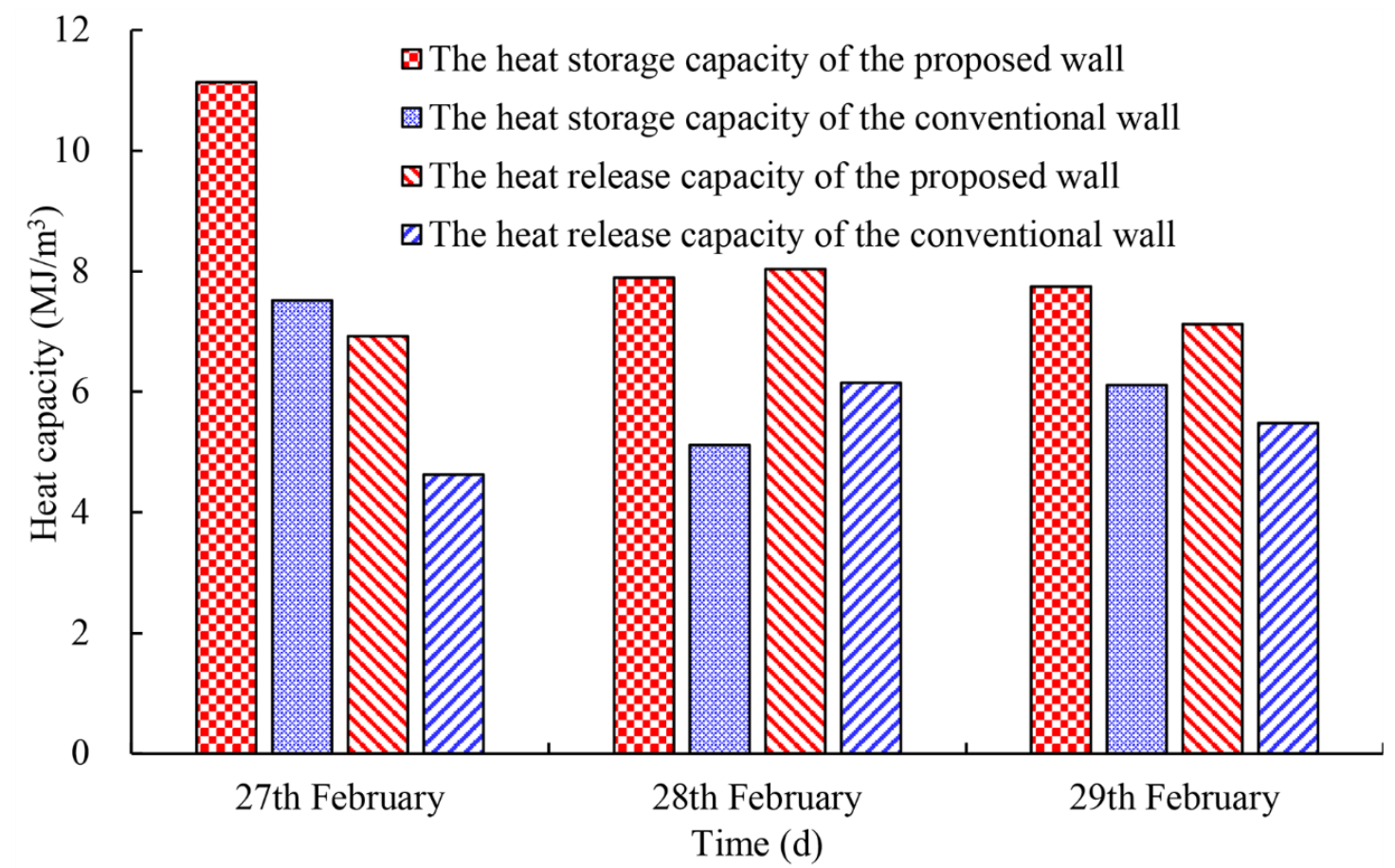

Figure 11: Heat storage/release capacity of both the conventional wall and the proposed wall.

\subsection{Indoor air temperature, thermal discomfort time and daily effective accumulative temperature}

The thermal performance of the north wall in greenhouses has an important influence on the indoor air temperature, especially during the nighttime. In order to justify the significance of this influence, indoor air temperatures measured from the solar greenhouses with the proposed wall and that with the conventional wall were compared, with results shown in Figure 12. During the daytime, solar radiation went into the solar greenhouse directly, causing the corresponding change of indoor air temperature in both parts of the solar greenhouse. Due to the opening of the bar vent between 13:30 and 15:30, cold outdoor air was brought into the solar greenhouses, resulting in a stable indoor air temperature or even declining trend. Since the heated air from solar collectors was sent into the proposed wall through air channels between 11:00 and 17:00, the solar greenhouse with the proposed wall obtained more heat. Therefore, its indoor air temperature went higher than that with the conventional wall. Their average temperature differences during the emphatic period were $4.09^{\circ} \mathrm{C}, 3.00^{\circ} \mathrm{C}$ and $4.43^{\circ} \mathrm{C}$, respectively. During the nighttime, heat started to be transferred from inside to the outside of the solar greenhouse due to the lower outdoor air temperature than indoor air temperature, causing a decrease of indoor air temperature. Thanks to the higher heat storage capacity provided by the proposed wall, the decreasing rate of the indoor air temperature with the proposed wall was lower than that with the conventional wall, and the temperature difference 
between the two parts of the greenhouse became larger with the change of time. Finally, the differences at the end of the night were $1.36^{\circ} \mathrm{C}, 1.80^{\circ} \mathrm{C}$ and $1.72^{\circ} \mathrm{C}$, respectively.

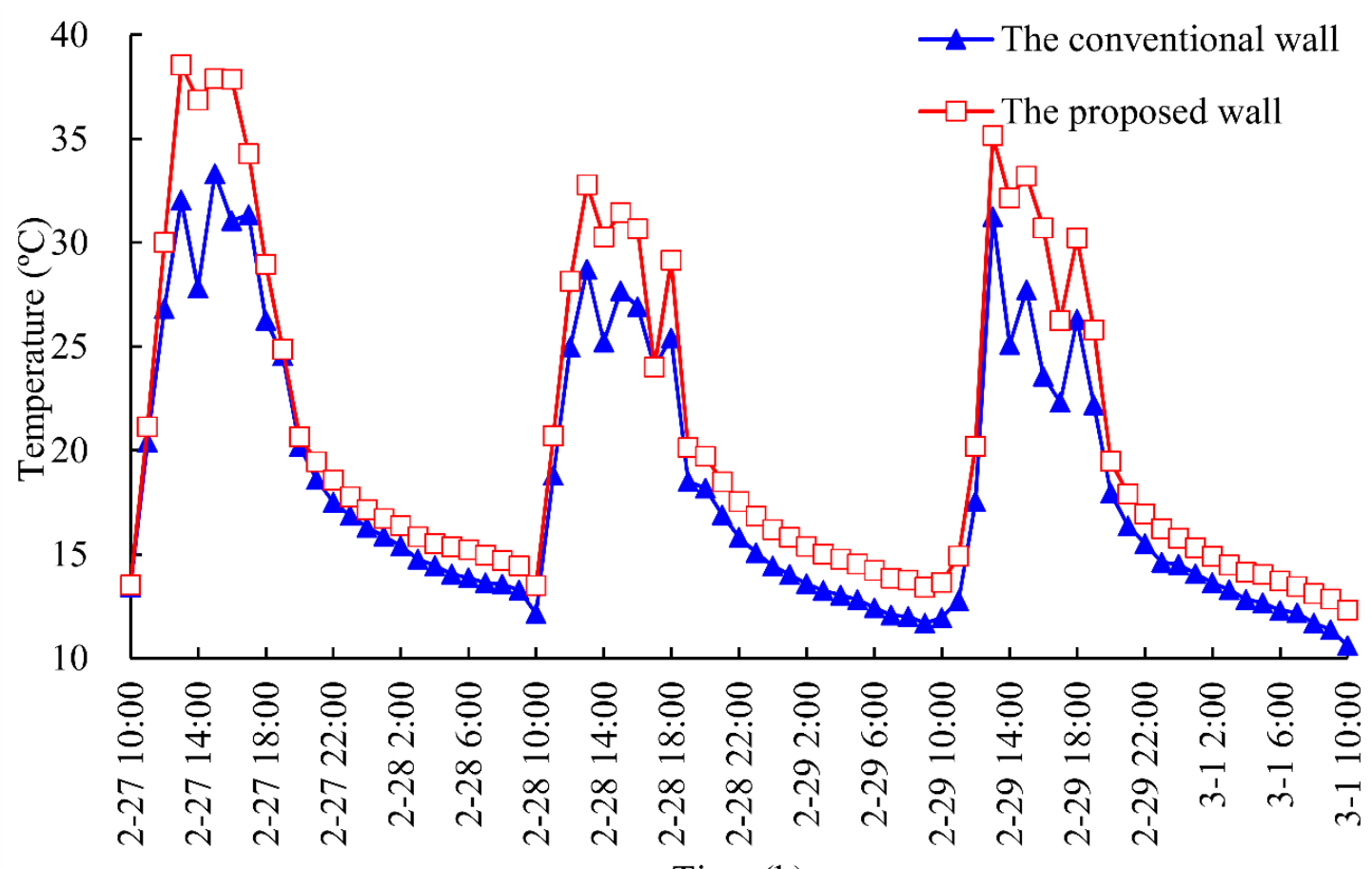

Time (h)

Figure 12: Indoor air temperatures of both solar greenhouses with the proposed wall and the conventional wall.

As stated earlier, crops can only grow healthily when the surrounding temperature is higher than the minimum temperature. Therefore, the thermal discomfort time and the daily effective accumulative temperature were counted and calculated, which are listed in Table 3. The thermal discomfort time with the proposed wall was less than that with the conventional wall, and the minimum measured indoor air temperature with the proposed wall was close to the minimum temperature during the thermal discomfort time. This means that the proposed wall could reduce the time and level of thermal discomfort. Additionally, the daily effective accumulative temperatures for the proposed wall were $179.12^{\circ} \mathrm{Ch}, 127.29^{\circ} \mathrm{Ch}$ and $125.36^{\circ} \mathrm{Ch}$, for the three days, and they were $44.77^{\circ} \mathrm{Ch}$ (33.33\%), $36.04^{\circ} \mathrm{Ch}(39.50 \%)$ and $44.52^{\circ} \mathrm{Ch}(55.06 \%)$ higher than those with the conventional wall, helpful to the growth of off-season crops.

Table 3. Thermal discomfort time and daily effective accumulative temperature.

\begin{tabular}{lllll}
\hline \multirow{2}{*}{ Time } & Section & $\begin{array}{l}\text { Minimum } \\
\text { indoor air } \\
\text { experimental } \\
\text { temperature } \\
{ }^{\circ} \mathrm{C}\end{array}$ & $\begin{array}{l}\text { Thermal } \\
\text { discomfort } \\
\text { time } \\
\mathrm{h}\end{array}$ & $\begin{array}{l}\text { Daily } \\
\text { effective } \\
\text { accumulative } \\
\text { temperature } \\
{ }^{\circ} \mathrm{Ch}\end{array}$ \\
\hline \multirow{2}{*}{ 2-27 } & With the conventional wall & 12.14 & 8 & 134.35 \\
& With the proposed wall & 13.50 & 4 & 179.12 \\
& Improvement & 1.36 & -4 & 44.77
\end{tabular}




\begin{tabular}{lllll}
\multirow{2}{*}{$2-28$} & With the conventional wall & 11.69 & 11 & 91.24 \\
& With the proposed wall & 13.42 & 7 & 127.29 \\
& Improvement & 1.72 & -4 & 36.04 \\
\multirow{2}{*}{$2-29$} & With the conventional wall & 10.61 & 12 & 80.85 \\
& With the proposed wall & 12.33 & 9 & 125.36 \\
& Improvement & 1.72 & -3 & 44.52 \\
\hline
\end{tabular}

\subsection{Soil temperature}

The soil temperature is critical for the seedling growth and root development. The proposed wall can promote the indoor air temperature, which has an influence on the soil temperature of the solar greenhouse. Figure 13 compares the soil temperature for the proposed wall and the conventional wall. It shows that the soil temperature with the proposed wall was always higher than that with the conventional wall, with average differences for the three days of $0.59^{\circ} \mathrm{C}, 0.90^{\circ} \mathrm{C}$ and $0.75^{\circ} \mathrm{C}$, respectively. After 10:00, the soil started to receive solar radiation. Due to the higher indoor air temperature with the proposed wall, the soil stored more heat, so its temperature began to rise. The soil temperature with the conventional wall started to rise after 12:00, two hours later than that with the proposed wall. After 18:00, the indoor air temperature with the conventional wall was lower than that with the proposed wall, so its soil would loss more heat to warm the indoor air, hence with the soil temperature starting to fall down. This pattern started after 19:00 for the greenhouse with the proposed wall, one hour later. The peak temperatures with the proposed wall were $26.28^{\circ} \mathrm{C}, 25.91^{\circ} \mathrm{C}$ and $24.65^{\circ} \mathrm{C}$, which were $0.53^{\circ} \mathrm{C}, 1.09^{\circ} \mathrm{C}$ and $0.74^{\circ} \mathrm{C}$ higher than that with the conventional wall.

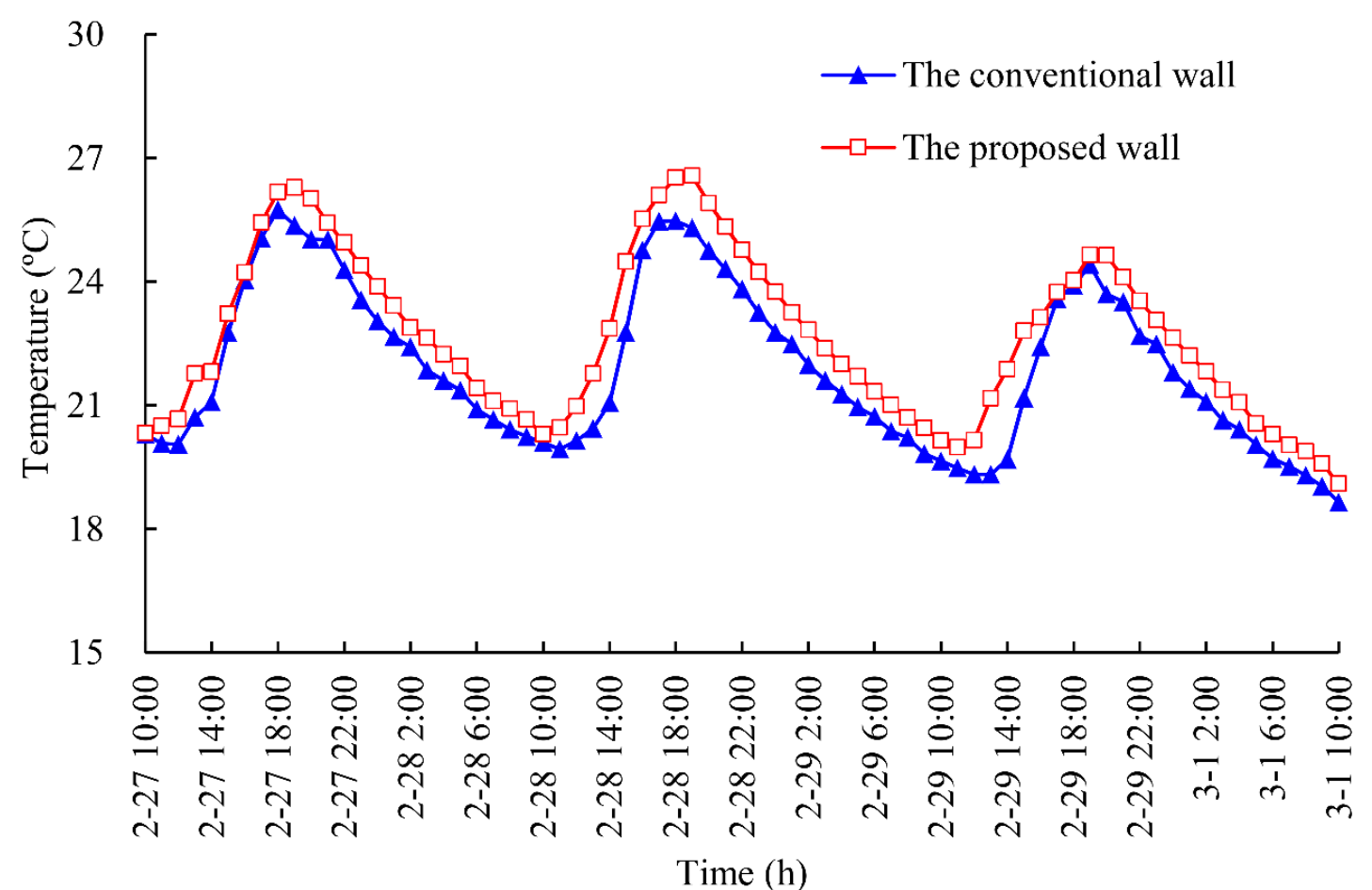

Figure 13: Soil temperature difference with the proposed wall and the conventional wall. 


\subsection{Growth status of crops}

The above analysis demonstrates a positive contribution of the proposed wall to providing a better thermal environment for off-season crops. In the last part of the analysis, the growth status of crops was used for the evaluation, in order to provide a more convincing justification.

\subsubsection{Plant height and stem diameter}

The height and stem diameter of plants in both solar greenhouses were collected in 90 consecutive days, and the results are compared Table 4 . The comparison reflects that the proposed wall had a significant contribution to promoting the plant height, with a more visible impact after 60 days, and the increasing rates were always higher than $30 \%$, with a peak at 80 days. The average height of plants in the part of the greenhouse with the proposed wall was $108.30 \mathrm{~cm}, 1.3$ times higher than those living in the part with the conventional wall. Similar conclusions for the stem diameter could be obtained as from the plant height: the average stem diameter of plants in the part of the greenhouse with the proposed wall was $11.7 \mathrm{~mm}, 25.45 \%$ larger than that of plants in the part with the conventional wall.

Table 4. Plant height and stem diameter.

\begin{tabular}{|c|c|c|c|c|}
\hline \multirow[b]{2}{*}{ Time } & \multicolumn{2}{|c|}{ Plant height (cm) } & \multicolumn{2}{|c|}{ Stem diameter $(\mathrm{mm})$} \\
\hline & $\begin{array}{l}\text { With the } \\
\text { proposed wall }\end{array}$ & $\begin{array}{l}\text { With the } \\
\text { conventional wall }\end{array}$ & $\begin{array}{l}\text { With the } \\
\text { proposed wall }\end{array}$ & $\begin{array}{l}\text { With the } \\
\text { conventional wall }\end{array}$ \\
\hline After 40 days & 55.84 & 49.70 & 9.5 & 6.6 \\
\hline After 50 days & 66.35 & 56.29 & 11.0 & 7.7 \\
\hline After 60 days & 78.54 & 69.04 & 11.9 & 9.4 \\
\hline After 70 days & 128.18 & 94.64 & 12.2 & 10.6 \\
\hline After 80 days & 157.14 & 107.94 & 12.8 & 11.2 \\
\hline After 90 days & 163.73 & 124.60 & 13.1 & 12.0 \\
\hline
\end{tabular}

\subsubsection{Fruit yield}

In this study, the daily fruit yield of matured tomatoes from both solar greenhouses was used as the last parameter to justify the advantages of the proposed wall, as shown in Figure 14. It can be easily seen that the greenhouse with the proposed wall provided higher daily fruit yield and total fruit yield. The daily maximum fruit yield due to the proposed wall was $133.02 \mathrm{~kg}, 1.16$ times as much as that due to the conventional wall. The total fruit yield due to the proposed wall was $1327.19 \mathrm{~kg}, 28.01 \%$ higher than that due to the conventional wall. Moreover, the proposed wall also shortened the growth cycle of crops. Tomatoes in the solar greenhouse with the proposed wall began to mature on $25^{\text {th }}$ March, while this date appeared to be $10^{\text {th }}$ April for the one with the conventional wall, 15 days earlier. 


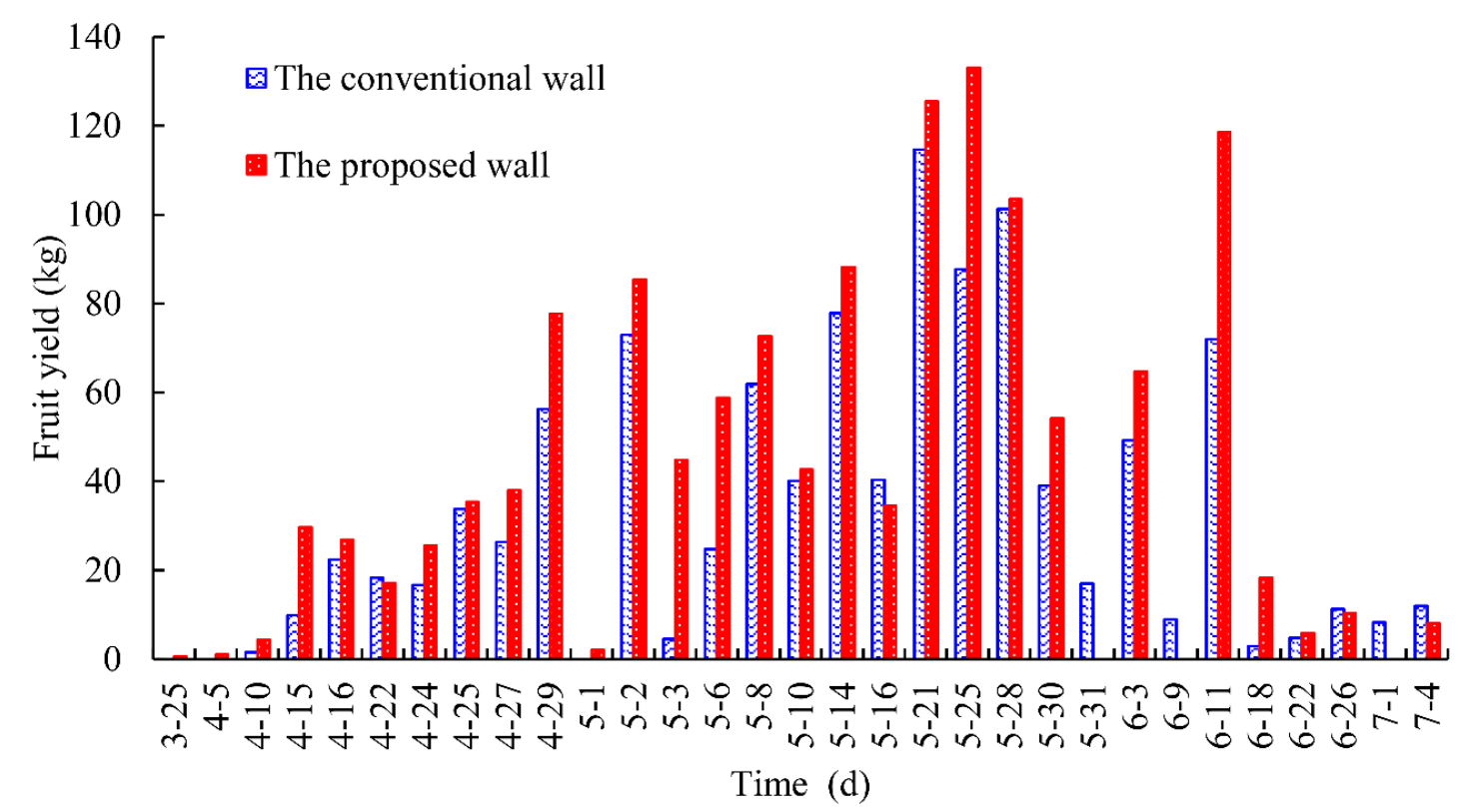

Figure 14: Fruit yield of solar greenhouses with the proposed wall and the conventional wall.

\section{Conclusions}

Currently, implementing PCM in the north wall has been suggested as an efficient solution for promoting the indoor thermal comfort of greenhouses, due to its high heat storage density and nearly isothermal nature during the charge/discharge process. Due to the limit of PCM with the low thermal conductivity, the absorbed heat could not be efficiently transferred to the middle layer of the walls, resulting in a thermal-stable layer inside the walls. The existence of this layer greatly decreases the walls' heat storage capacity. In order to solve this problem, an active-passive ventilation wall with phase change material has been proposed in this study. To justify its advantages over conventional walls, a comparative study was designed and carried out, and a twodimensional unsteady numerical heat transfer model was established. Many important parameters were either monitored or calculated to indicate the contribution of the newly proposed method to the middle layer of the wall, the indoor thermal environment and the occupants' growth. Some major findings from this study include,

(1) The proposed wall can effectively promote the temperature of the middle layer of walls in solar greenhouses. No thermal-stable layer has been observed inside the proposed wall, resulting in a minimum temperature rise of $1.34^{\circ} \mathrm{C}$.

(2) PCM and ventilation applied in the proposed solution can increase the wall's irradiated surface temperature, with the temperature rise of $2.01-2.67^{\circ} \mathrm{C}$ for $\mathrm{PCM}$ during the nighttime and $0.98-1.04^{\circ} \mathrm{C}$ for ventilation during the daytime.

(3) The proposed solution can significantly enhance the wall's heat storage capacity 
during the daytime and the heat release capacity during the nighttime. The increase rate of heat storage capacity and heat storage capacity were $35.27 \%-47.89 \%$ and 49.93\%-60.21\%, respectively, during the investigating period.

(4) The proposed solution has a positive impact on the indoor air temperature, daily effective accumulative temperature and soil temperature, with the average increase of $1.58-4.16^{\circ} \mathrm{C}$ for indoor air temperature, $33.33 \%-55.06 \%$ for daily effective accumulative temperature, and $0.53-1.09^{\circ} \mathrm{C}$ for soil temperature.

(5) The proposed solution has a significant contribution to improving the growth status of crops and also shortening their growth cycle. The plant height and stem diameter were improved by $30 \%$ and $25 \%$, respectively. The growth cycle of crops was shortened by almost 15 days, and the fruit yield of plants was improved by $28 \%$.

\section{Acknowledgements}

This work is supported by National Natural Science Foundation of China (Grant No. 51578012), National key research and development program of China (Grant No. 2016YFC0700206) and Beijing Natural Science Foundation (Grant No.8184095).

\section{References}

[1] Zhang L, Xu P, Mao JC, Tang X, Li ZW, Shi JG. A low cost seasonal solar soil heat storage system for greenhouse heating: Design and pilot study. Appl Energ. 2015;156:213-22.

[2] Cossu M, Murgia L, Ledda L, Deligios PA, Sirigu A, Chessa F, et al. Solar radiation distribution inside a greenhouse with south-oriented photovoltaic roofs and effects on crop productivity. Appl Energ. 2014;133:89-100.

[3] Vadiee A, Martin V. Thermal energy storage strategies for effective closed greenhouse design. Appl Energ. 2013;109:337-43.

[4] Mohammadi A, Omid M. Economical analysis and relation between energy inputs and yield of greenhouse cucumber production in Iran. Appl Energ. 2010;87:191-6.

[5] Ling HSA, Chen C, Wei S, Guan Y, Ma CW, Xie GY, et al. Effect of phase change materials on indoor thermal environment under different weather conditions and over a long time. Appl Energ. 2015;140:329-37.

[6] Xu J, Li Y, Wang RZ, Liu W, Zhou P. Experimental performance of evaporative cooling pad systems in greenhouses in humid subtropical climates. Appl Energ. 2015;138:291-301.

[7] Mezrhab A, Elfarh L, Naji H, Lemonnier D. Computation of surface radiation and natural convection in a heated horticultural greenhouse. Appl Energ. 2010;87:894-900.

[8] Wei B, Guo SR, Wang J, Li J, Wang JW, Zhang J, et al. Thermal performance of single span greenhouses with removable back walls. Biosyst Eng. 2016;141:48-57.

[9] Wei B, Guo S, Li J, Li S, Wang J, Wang J, et al. Design and Experimental Evaluation of Greenhouses with Removable Back Walls. Appl Eng Agric. 2015;31:633-42. 
[10] Du J, Bansal P, Huang B. Simulation model of a greenhouse with a heat-pipe heating system. Appl Energ. 2012;93:268-76.

[11] Sethi VP, Sharma SK. Survey and evaluation of heating technologies for worldwide agricultural greenhouse applications. Sol Energy. 2008;82:832-59.

[12] Zhang X, Wang HL, Zou ZR, Wang SJ. CFD and weighted entropy based simulation and optimisation of Chinese Solar Greenhouse temperature distribution. Biosyst Eng. 2016;142:12-26.

[13] Ramakrishnan S, Wang XM, Sanjayan J, Wilson J. Thermal performance of buildings integrated with phase change materials to reduce heat stress risks during extreme heatwave events. Appl Energ. 2017;194:410-21.

[14] Yataganbaba A, Ozkahraman B, Kurtbas I. Worldwide trends on encapsulation of phase change materials: A bibliometric analysis (1990-2015). Appl Energ. 2017;185:720-31.

[15] Ye RD, Lin WZ, Yuan KJ, Fang XM, Zhang ZG. Experimental and numerical investigations on the thermal performance of building plane containing $\mathrm{CaCl} 2$ center dot $6 \mathrm{H}(2) \mathrm{O} /$ expanded graphite composite phase change material. Appl Energ. 2017;193:325-35.

[16] Sharshir SW, Peng GL, Wu LR, Essa FA, Kabeel AE, Yang N. The effects of flake graphite nanoparticles, phase change material, and film cooling on the solar still performance. Appl Energ. 2017;191:358-66.

[17] Lei JW, Kumarasamy K, Zingre KT, Yang JL, Wan MP, Yang EH. Cool colored coating and phase change materials as complementary cooling strategies for building cooling load reduction in tropics. Appl Energ. 2017;190:57-63.

[18] Huang X, Alva G, Liu LK, Fang GY. Microstructure and thermal properties of cetyl alcohol/high density polyethylene composite phase change materials with carbon fiber as shape-stabilized thermal storage materials. Appl Energ. 2017;200:19-27.

[19] Guarino F, Athienitis A, Cellura M, Bastien D. PCM thermal storage design in buildings: Experimental studies and applications to solaria in cold climates. Appl Energ. 2017; 185:95-106.

[20] Berroug F, Lakhal EK, El Omari M, Faraji M, El Qarnia H. Thermal performance of a greenhouse with a phase change material north wall. Energ Buildings. 2011;43:3027-35.

[21] Najjar A, Hasan A. Modeling of greenhouse with PCM energy storage. Energ Convers Manage. 2008;49:3338-42.

[22] Guan Y, Chen C, Han YQ, Ling HS, Yan QY. Experimental and modelling analysis of a three-layer wall with phase-change thermal storage in a Chinese solar greenhouse. J Build Phys. 2015;38:548-59.

[23] Singh RD, Tiwari GN. Thermal heating of controlled environment greenhouse: a transient analysis. Energ Convers Manage. 2000;41:505-22.

[24] Kumari N, Tiwari GN, Sodha MS. Effect of phase change material on passive thermal heating of a greenhouse. Int J Energ Res. 2006;30:221-36.

[25] Tong G, Christopher DM, Li B. Numerical modelling of temperature variations in a Chinese solar greenhouse. Comput Electron Agr. 2009;68:129-39.

[26] Tiwari GN, Din M, Srivastava NSL, Jain D, Sodha MS. Evaluation of solar fraction 
(F-n) for the north wall of a controlled environment greenhouse: an experimental validation. Int J Energ Res. 2002;26:203-15.

[27] Ling HS, Chen C, Guan Y, Wei S, Chen ZG, Li N. Active heat storage characteristics of active-passive triple wall with phase change material. Sol Energy. 2014;110:276-85.

[28] Ling HS, Chen C, Qin H, Wei S, Lin J, Li N, et al. Indicators evaluating thermal inertia performance of envelops with phase change material. Energ Buildings. 2016;122:175-84.

[29] Wang JW, Li SH, Guo SR, Ma CW, Wang J, Jin S. Simulation and optimization of solar greenhouses in Northern Jiangsu Province of China. Energ Buildings. 2014;78:143-52.

[30] Li YC, Liu SL. Experimental study on thermal performance of a solar chimney combined with PCM. Appl Energ. 2014;114:172-8.

[31] Jaworski M. Thermal performance of building element containing phase change material (PCM) integrated with ventilation system - An experimental study. Appl Therm Eng. 2014;70:665-74.

[32] Evola G, Marletta L, Sicurella F. Simulation of a ventilated cavity to enhance the effectiveness of PCM wallboards for summer thermal comfort in buildings. Energ Buildings. 2014;70:480-9.

[33] El Mankibi M, Zhai ZQ, Al-Saadi SN, Zoubir A. Numerical modeling of thermal behaviors of active multi-layer living wall. Energ Buildings. 2015;106:96-110.

[34] Diarce G, Campos-Celador A, Martin K, Urresti A, Garcia-Romero A, Sala JM. A comparative study of the CFD modeling of a ventilated active fa ade including phase change materials. Appl Energ. 2014;126:307-17.

[35] Diarce G, Urresti A, Garcia-Romero A, Delgado A, Erkoreka A, Escudero C, et al. Ventilated active facades with PCM. Appl Energ. 2013;109:530-7.

[36] Chen C, Guo HF, Liu YN, Yue HL, Wang CD. A new kind of phase change material (PCM) for energy-storing wallboard. Energ Buildings. 2008;40:882-90.

[37] Tong GH, Christopher DM, Li TL, Wang TL. Passive solar energy utilization: A review of cross-section building parameter selection for Chinese solar greenhouses. Renew Sust Energ Rev. 2013;26:540-8.

[38] Chen W, Liu W. Numerical simulation of the airflow and temperature distribution in a lean-to greenhouse. Renew Energ. 2006;31:517-35.

[39] Zhang BG, Fan XY, Liu M, Hao WG. Experimental study of the burning-cave hot water soil heating system in solar greenhouse. Renew Energ. 2016;87:1113-20.

[40] Li T. Theory and practice on vegetable cultivation in solar greenhouse. Beijing: China agriculture press; 2013.

[41] Holman JP. Heat transfer. 10 ed. New York: McGraw-Hill Education; 2009.

[42] Peaceman DW, Rachford HH. The Numerical Solution of Parabolic and Elliptic Differential Equations. J Soc Ind Appl Math. 1955;3:28-41. 